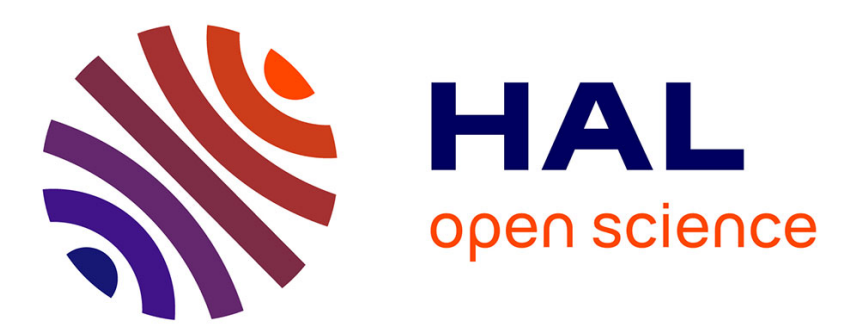

\title{
A molecular dynamics simulation study of three polysulfones in dry and hydrated states
}

Grégory Marque, Jacques Verdu, Valéry Prunier, David Brown

\section{To cite this version:}

Grégory Marque, Jacques Verdu, Valéry Prunier, David Brown. A molecular dynamics simulation study of three polysulfones in dry and hydrated states. Journal of Polymer Science Part B: Polymer Physics, 2010, 48 (22), pp.2312-2336. 10.1002/polb.22117 . hal-02456666

\section{HAL Id: hal-02456666 https://hal.science/hal-02456666}

Submitted on 27 Jan 2020

HAL is a multi-disciplinary open access archive for the deposit and dissemination of scientific research documents, whether they are published or not. The documents may come from teaching and research institutions in France or abroad, or from public or private research centers.
L'archive ouverte pluridisciplinaire HAL, est destinée au dépôt et à la diffusion de documents scientifiques de niveau recherche, publiés ou non, émanant des établissements d'enseignement et de recherche français ou étrangers, des laboratoires publics ou privés. 


\title{
A Molecular Dynamics Simulation Study of Three Polysulfones in Dry and Hydrated States
}

\author{
GRÉGORY MARQUE, ${ }^{1}$ JACQUES VERDU, ${ }^{2}$ VALÉRY PRUNIER, ${ }^{3}$ DAVID BROWN ${ }^{1}$ \\ ${ }^{1}$ LMOPS, UMR CNRS 5041, Université de Savoie, Bâtiment IUT, 73376 Le Bourget-du-Lac, France \\ ${ }^{2}$ LIM, UMR CNRS 8006, ENSAM, 151 Boulevard de I'Hôpital, Paris 75013, France \\ ${ }^{3}$ EDF R\&D, Site des Renardières, Moret-sur-Loing 77818, France
}

\begin{abstract}
Molecular dynamics (MD) simulations of three polysulfones (poly(ether sulfone) PESU, poly(phenylene sulfone) PPSU and polysulfone PSU) in dry and hydrated states were undertaken in order to study the specific interactions between water and glassy polymer matrices of the same structural family. Dry polysulfone models were generated using a hybrid pivot Monte Carlo-MD single-chain sampling technique and the resulting relaxed densities were found to be in close agreement with experimental data. Hydrated systems are found to reproduce quite well volumetric changes experimentally observed. The concentrations of sulfonic groups can explain qualitatively their different water solubilities. Water is preferentially hydrogenbonded to two sites which either link two polymer sites, or one polymer site and another water, or two other waters. A detailed
\end{abstract}

analysis of these water bridges that are formed is presented. Only a small quantity of potential bridging sites are occupied for water contents near the experimental saturation. The free fractional volumes, the probe accessible volumes, the swelling of the polymers, the water-polymer interactions and the hydrogen bond lifetimes, are also presented for these polysulfones. Water-water interactions and water clusters are found to be more important in the more hydrophilic PESU in comparison to the less hydrophilic PSU.

KEYWORDS: bridges; clusters; hydrogen bonds; molecular dynamics; poly(ether sulfone); poly(phenylene sulfone); poly(sulfones); simulations; water
INTRODUCTION The influence of absorbed water on structural, $^{1-21}$ physical, $^{1,11,18,21-37}$ mechanical, ${ }^{3,14,18,21,32,38-43}$ and electrical properties ${ }^{37,44-48}$ of polymers has been extensively studied and the consequent effects this can have during plastic processing has been highlighted. ${ }^{4}$ Hydrolysis of polymers by water is also a well-known phenomenon.,18,43,49-61 For all these reasons, water sorption has been studied for many years mainly using techniques such as sorption isotherms, ${ }^{24,50,62-76}$ density or swelling measurements, ${ }^{1,11,22-35,49,77}$ differential scanning calorimetry (DSC), ${ }^{12,78-81}$ infrared experiments, ${ }^{6,28,81-100}$ dielectric measurements $24,98,101,102$ or nuclear magnetic resonance (NMR). ${ }^{12,78,79,102-106}$ Other specific experimental techniques have also been applied. The results of such experiments have mainly been interpreted in terms of Langmuir or Henry sorption mechanisms and water cluster existence (for the sorption isotherms), hole filling mechanism or additivity of water and polymer volumes (for density measurements), presence of "free" water (for DSC), hydrogen bonds and water arrangement (for IR), and "free" water and water linked to the polymer (for dielectric measurements and NMR). Such measurements have also given rise to, and been used to discredit, a number of theories that have been proposed to explain water sorption in polymers. A relationship between the water solubility and the free fractional volume (FFV) of a polymer has been rejected by Schult et al. in a study on several polymers of a same structural family. ${ }^{63} \mathrm{~A}$ correlation between the free space and the water sorption ${ }^{107}$ has been discarded. ${ }^{49,64,108-110}$ Water absorption has also been directly correlated to the molecular formula of the polymer through a molar additive function of terms due to the constitutive groups of the monomer. ${ }^{111}$ Attempts have also been made to apply the classical thermodynamic approach of polymer-solvent miscibility. ${ }^{111,112}$ Nevertheless, no real explanations of the underlying mechanisms have been provided by the aforementioned theories. ${ }^{49,64,108,109}$ Some authors have proposed that water molecules are doubly hydrogen bonded with hydrophilic sites in nylon $6{ }^{62}$ poly(ether imide), ${ }^{77}$ amine/epoxy network, ${ }^{49}$ or polysulfones. ${ }^{64,108}$ Interpretations of infrared spectra of other polymers have also considered such "water bridges." ${ }^{83,88,98}$ From the variations of the water dissolution enthalpies in poly(ether sulfone) (PESU), poly(phenylene sulfone) (PPSU), and 


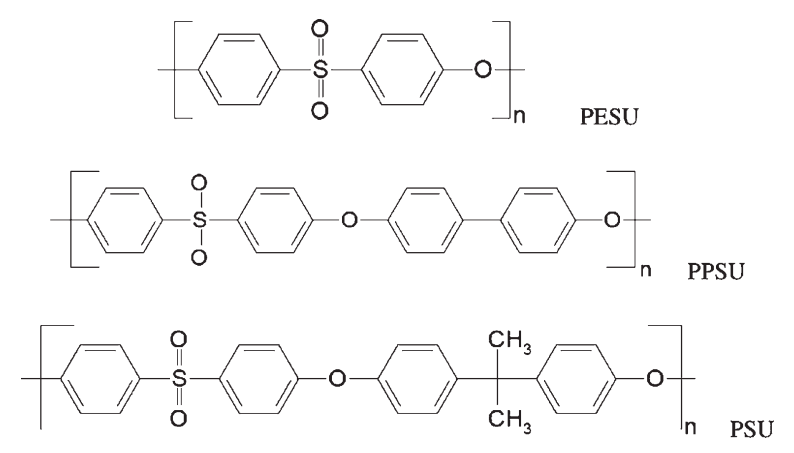

FIGURE 1 The chemical structures of poly(ether sulfone) (PESU), poly(phenylene sulfone) (PPSU), and polysulfone (PSU).

polysulfone (PSU; see structures in Fig. 1), Gaudichet et al. have proposed that all water molecules are always doubly hydrogen bonded to two hydrophilic sites on the polymer in which case water solubility should be directly linked to the pair distribution of these hydrophilic sites. ${ }^{64,108}$

Molecular dynamics (MD) simulations are of particular interest to test such hypotheses concerning the structure at the molecular scale. Many MD studies of hydrated bulk polymers like PESU, ${ }^{113} \mathrm{PA}^{114-116}$ amide-based structures, ${ }^{117-120}$ $\mathrm{PMMA}^{121}$ BPA-PC, ${ }^{122}$ PEI, ${ }^{123}$ PVA, ${ }^{122,124-131}$ EVOH copolymers, ${ }^{132}$ PEO, ${ }^{133}$ PEO-based polymer electrolytes, ${ }^{134,135}$ perfluorinated ionomers, ${ }^{136,137}$ poly(phenylene sulfones), ${ }^{138}$ sulfonated polyimides, ${ }^{139} \mathrm{PE},{ }^{140-142} \mathrm{PDMS}^{141-144} \mathrm{PP}^{145}$ epoxy resins, ${ }^{98,146-148}$ polystyrene and copolymers, ${ }^{149}$ rubbers, ${ }^{150}$ polyacrylates, ${ }^{151}$ polyesters, ${ }^{152}$ or biopolymers ${ }^{153-155}$ have now been reported in the literature. They put forward water-polymer and water-water interactions through hydrogen bonds. Water clusters have been observed in different polymers (PE, PP, PS, SBR, EVOH, PA 6-6, PMDAODA), ${ }^{115,132,140,141,145,149,150,156}$ using different water models, such as SPC/E, ${ }^{115,141,156}$ TIP4P, ${ }^{140,145}$ or models available in commercial codes, ${ }^{98,132,149}$ and cluster sizes can exceed 10 $\mathrm{H}_{2} \mathrm{O}$ molecules. ${ }^{115,156}$ However, the same model of water has been found to form clusters in some hydrated polymer systems and not in others. ${ }^{149,150}$ In the same vein, for the same polymer matrix, Tamai et al. ${ }^{141}$ find water clusters whereas Fritz et al. ${ }^{143}$ do not; a result the latter explain by the use of a different water potential. Nevertheless, water cluster existence indicates that water interactions in a polymer can not be limited to interactions with polymer sites.

Several simulations have shown that water molecules diffuse in the polymer by a jump mechanism. ${ }^{116,118,129,131,141,143,145,149}$ For some authors, it implies cooperative motions of the polymer matrix and of the $\mathrm{H}_{2} \mathrm{O}$ molecules. ${ }^{118,126}$ The Einstein diffusion regime is not always attainable for hydrated polymers under simulations of several nanoseconds near ambient temperature due to the diffusion coefficient of water being too low. ${ }^{116,119,149,150}$ Few studies report the density variations of the models with the water content. Only an initial increase followed by a decrease of the density of PA 6-6 and an epoxy resin have been reported, ${ }^{115,148}$ as well as a continuous decrease of the density for PMMA above its glass transition temperature. ${ }^{121}$

Very short-time simulations $(<200 \mathrm{ps})$ on dense models of polysulfone oligomers $(<12$ monomers of PESU, PSU, or PPSU) have been carried out. ${ }^{157-161}$ These PSU models have been used to examine their mechanical, ${ }^{158}$ thermal, ${ }^{158,159}$ and dynamic properties. ${ }^{157,159,160}$ Gas transport properties have also been studied in PSU, ${ }^{160,161}$ PESU and PPSU systems. ${ }^{160}$ Few simulations have been carried out on longchain polysulfone models. ${ }^{113,162-165}$ However, the method of growing the chains used by Ahn et al., ${ }^{113}$ Hölck et al., ${ }^{163,164}$ and Heuchel et al. ${ }^{162}$ is known to give a bias in the configurations because of the ever-increasing density. ${ }^{166}$ Furthermore, these authors use a complicated series of heatingcooling and compression-decompression cycles to try and approach the experimental density of the polymers. Despite this procedure, the densities of their models are only within $\sim 5 \%{ }^{113}$ and $\sim 2.7 \%$ for PESU $^{162}$ and $\sim 3 \%$ for PSU. ${ }^{162-164}$ This may not only be linked to the parameters used but also to the generation procedure. ${ }^{167}$

Here, we apply a simpler and more reliable amorphous sample generation procedure to three long-chain polysulfone models (PESU, PPSU, and PSU) and simulate these systems in dry and hydrated states. The interaction potential is presented in "Interaction Potential" section. In "Dry Polysulfones" section, the hybrid pivot Monte Carlo-Molecular Dynamics (PMC-MD) technique $\mathrm{e}^{167-179}$ is validated for these polysulfones and used to generate bulk models. In "Hydrated Polysulfones" section, different hydrated systems with different water contents are simulated and analyzed in terms of swelling, energetic properties, specific interactions between polymer, and water, existence of "water bridges," water clusters and water mobility as a function of the water content.

\section{INTERACTION POTENTIAL}

The force field for polysulfones is based on the same as that already described for various polyimides ${ }^{167,171,172,180}$ and used recently for PMDA-ODA. ${ }^{156}$ Only the main features will be outlined here. All bonds are modeled as rigid constraints ${ }^{181}$ so as to eliminate all the very high-frequency bond stretching modes. This allows for the use of an integration time step, $\Delta t$, of $10^{-15} \mathrm{~s}$ and avoids problems with the equipartition of kinetic energy. Continuous analytical "bonded" potentials are used to describe the energies associated with angle-bending, torsional rotations around the dihedral angles, and out-of-plane distortions of planar $s p^{2}$ structures. "Nonbonded" pair potentials are applied to all atom pairs belonging to different molecules and also between those on the same molecule that are separated by more than two bonds. The Van der Waals interactions between atoms of types $i$ and $j$ are of the Lennard-Jones (LJ) 12-6 form. The Ewald summation method is used to calculate the electrostatic potential. ${ }^{182,183}$ Polysulfone parameters were mainly taken from TRIPOS 5.2 force field. ${ }^{184}$ However, this force field does not contain some parameters associated to the sulfonic group. For this reason, parameters for the $\mathrm{S}-0$ bond, the $\mathrm{C}-\mathrm{S}-\mathrm{C}$ flexion angle, the $\mathrm{C}-\mathrm{C}-\mathrm{S}-\mathrm{C}$ and 
$\mathrm{C}-\mathrm{C}-\mathrm{S}-\mathrm{O}$ torsion angles were taken from MM3. ${ }^{185}$ Partial charges were obtained by doing $a b$ initio calculations using the Gaussian computer program ${ }^{186}$ at the B3LYP/6-31G** level on small fragments. ${ }^{171}$ The actual values have been reported elsewhere. ${ }^{187}$

As for PMDA-ODA, ${ }^{156}$ the water model chosen is the extended single point charge model, SPC/E, ${ }^{188}$ and LorentzBerthelot combination rules ${ }^{189}$ were used to obtain the Van der Waals parameters for the interactions between water and the polymer. The MD simulations were performed using the gmq program ${ }^{190}$ either in its scalar or in its parallel form on the Linux servers of the LMOPS and the University of Savoie as well as on the EDF "Rendvous" cluster in France.

\section{DRY POLYSULFONES}

\section{Hybrid Pivot PMC-MD Single-Chain Sampling}

The starting configurations for the polysulfones have been generated by the hybrid PMC-MD method ${ }^{175}$ which has already been validated for a large variety of polymer chains. ${ }^{167}$ With this technique, the configurational phase-space of a single polymer chain is efficiently sampled by interspersing occasional pivot Monte Carlo (PMC) moves ${ }^{191}$ for rotatable torsions, whilst performing standard molecular dynamics. As the method is based on Flory's hypothesis ${ }^{192}$ that polymer configurations in the pure melt are only governed by nearneighbor intramolecular interactions, only a certain number of specific near-neighbor intramolecular interactions are considered between atoms separated by no more than a fixed number of backbone bonds ( $n_{\text {bonds }}$ ). Above the glass transition temperature $\left(T_{\mathrm{g}}\right)$, this procedure leads to chain configurations similar to those obtained by doing MD with the full potential in the bulk melt. The procedure to define and validate $n_{\text {bonds }}$ is thus to compare the configurational and conformational properties of chains sampled by the PMC-MD method ("single-chain") with those of a fully interacting dense system of the same chains decorrelated by MD only ("bulk melt"). However, to decorrelate the bulk melt chains within a timescale accessible to MD simulations, this test is carried out both at high temperature and on short oligomers. In general, it has been found that optimum value of $n_{\text {bonds }}$ is independent of chain length so the extension to longer chains is straightforward. ${ }^{167}$

To optimize $n_{\text {bonds }}$ for the three types of polysulfone, "singlechain" test systems containing one 4-mer chain were simulated for $10,000 \mathrm{ps}$ at $750 \mathrm{~K}$ with the PMC-MD method for a range of values of $n_{\text {bonds. }}$ For the "bulk melt" simulations, boxes containing 27 such oligomers were first constructed. MD simulations were then carried out for 15,000 ps under NpT conditions at $750 \mathrm{~K}$ in which the isotropic pressure, $p$, was maintained at 1 bar by loose coupling, with a coupling constant of $5 \mathrm{ps}^{193}$ and the temperature, $T$, was held constant by weak coupling to a heat bath with a coupling constant of 0.1 ps. $^{194}$ Optimum parameters for the Ewald $\operatorname{sum}^{195,196}$ were $\alpha=0.27, K_{\max }=9$ and $R_{\mathrm{c}}=7.5 \AA$ for the PESU and PPSU systems, and $\alpha=0.25, K_{\max }=9$ and $R_{\mathrm{c}}=$ $9 \AA$ for PSU. The Van der Waals potentials were truncated at

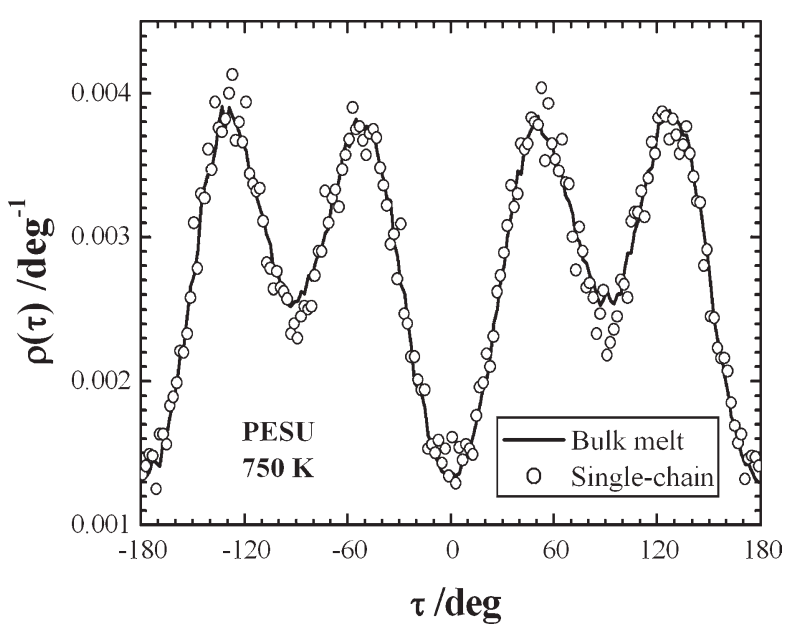

FIGURE 2 Single-chain-sampled (circles) vs. bulk melt (line) probability densities for the $\mathrm{C}-\mathrm{C}-\mathrm{O}-\mathrm{C}$ pivot torsion angle in 4-mer PESU chains using $n_{\text {bonds }}=4$ at $750 \mathrm{~K}$.

$9 \AA$ in all systems and standard long-range corrections to the energy and the pressure were applied. ${ }^{189}$

The decorrelation of the chains from their initial configurations was monitored by calculating the normalized autocorrelation functions for the end-to-end vector, $\mathbf{R}_{i}$, of the individual chains as a function of time:

$$
C_{\mathrm{R}}(t)=\frac{\left\langle\mathbf{R}_{i}(0) \mathbf{R}_{i}(t)\right\rangle-\left\langle\mathbf{R}_{i}\right\rangle^{2}}{\left\langle\mathbf{R}_{i}^{2}\right\rangle-\left\langle\mathbf{R}_{i}\right\rangle^{2}}
$$

The results (not shown) demonstrate that 8 ns is sufficient to decorrelate the end-to-end vector of the chains in all systems. The 4-mer PESU chains decorrelate notably faster due to their shorter length.

In Figure 2, the distributions of the $\mathrm{C}-\mathrm{C}-\mathrm{O}-\mathrm{C}$ pivot torsion angle, $\tau$, for both single-chain and bulk-melt relaxed chains of PESU are shown. This torsion angle has been found to be the most sensitive to the $n_{\text {bonds }}$ value. Singlechain distributions for PESU are in good agreement with the bulk melt ones for a value of $n_{\text {bonds }}=4$. The same value also gives good results for PPSU and PSU. A value of $n_{\text {bonds }}=4$ is also found to be appropriate in the case of the $\mathrm{C}-\mathrm{C}-\mathrm{S}-\mathrm{C}$ and $\mathrm{C}-\mathrm{C}-\mathrm{C}-\mathrm{C}$ torsional angles for all three polysulfones studied here. Similar good agreement (not shown) is also found for the distributions of the mean square end-to-end distances $\left\langle R^{2}\right\rangle$ and mean-square radii of gyration $\left\langle S^{2}\right\rangle$. The value of $n_{\text {bonds }}=4$ was thus considered optimal for its subsequent use in PMC-MD calculations for longer chains and for generating starting configurations of PESU, PPSU, and PSU for the multichain MD simulations of the bulk amorphous phases.

To choose an appropriate length of chain to use in the bulk simulations, PMC-MD calculations on single chains of PESU, PPSU, and PSU of different sizes (expressed in number of monomers $n_{\text {monomers }}$ ) with $n_{\text {bonds }}=4$ were carried out. These showed that the ratio $\left\langle R^{2}\right\rangle / n_{\text {monomers }}$ becomes 
TABLE 1 The Number of Chains in the System $\left(n_{\text {chains }}\right)$, Number of Monomers Per Chain ( $n_{\text {monomers }}$ ), Total Number of Atoms Per System $\left(n_{\text {atoms }}\right)$, and Convergence Parameters for the Ewald Sum and Van der Waals Potential for the Three Polysulfone Systems

\begin{tabular}{lllllrrr}
\hline Polysulfone & $n_{\text {chains }}$ & $n_{\text {monomers }} /$ chain & $n_{\text {atoms }}$ & $\alpha$ & $K_{\max }$ & $R_{\mathrm{c}} / \AA$ & $R_{\mathrm{VdW}} / \AA$ \\
PESU & 20 & 100 & 48,100 & 0.19 & 11 & 11.5 \\
PPSU & 20 & 50 & 45,100 & 0.17 & 9 & 11.5 \\
PSU & 20 & 50 & 54,100 & 0.20 & 12 & 11.5
\end{tabular}

number-independent for $n_{\text {monomers }}$ in excess of about 20; the plateau values being $\sim 135$ (or $\sim 270$ if we consider the PESU unit being 2 monomers long), $\sim 320$ and $\sim 265 \AA^{2}$ for PESU, PPSU, and PSU, respectively. To have similar chain lengths for the polysulfones in the remaining studies, chains of 50 monomers were constructed for PPSU and PSU whereas chains of 100 monomers were used for PESU. Given the chemical structures (Fig. 1), this leads to all chains having the same number of cyclic rings. Moreover, experimental measurements of number molar mass $\left(M_{\mathrm{n}}\right)$ report $\overline{M_{\mathrm{n}}^{\text {PESU }}}=$ $26,675 \mathrm{~g} \mathrm{~mol}^{-1}$ and $\overline{M_{\mathrm{n}}^{\mathrm{PSU}}}=20,810 \mathrm{~g} \mathrm{~mol}^{-1} ;{ }^{64}$ values which can be used to obtain the average number of monomers per chain by calculating the degree of polymerization, $D P_{\mathrm{n}}$,

$$
D P_{\mathrm{n}}=\frac{\overline{M_{\mathrm{n}}}}{M_{0}}
$$

where $M_{0}$ is the molar mass of one monomer. This gives average experimental chain lengths of $\sim 115$ and $\sim 47$ monomers for PESU and PSU, respectively. Corresponding weight molar mass $\left(M_{\mathrm{w}}\right)$ have also been given equal to 70,421 $\mathrm{g}$ $\mathrm{mol}^{-1}$ and 49,944 $\mathrm{g} \mathrm{mol}^{-1}$ in the same work. ${ }^{64}$ Other experimental values of $M_{\mathrm{w}}$ have been reported to be $49,000 \mathrm{~g}$ $\mathrm{mol}^{-1}$ and 39,000 $\mathrm{g} \mathrm{mol}^{-1}$ for PESU and PSU, respectively. ${ }^{197}$ Thus the size of the chains in our simulations are comparable to those used experimentally.

\section{Generation of Dense Polysulfone Models}

In the laboratory, the synthesis of polysulfones is generally carried out by polycondensation of $4,4^{\prime}$-dichlorodiphenyl sulfone with the respective phenolic monomer, i.e., the dihydroxy diphenyl sulfone for the PESU, the biphenol for the PPSU and the bisphenol A for the PSU. To terminate the polymerization, methyl chloride can be added into the polymerizing mixture and the reaction involves the conversion of aryl oxide ends to their respective methyl ethers. ${ }^{198}$ Thus, theoretically, chain ends should be $50 \%$ chlorine and $50 \%$ methoxy endgroups. A BASF correspondent advised us that in reality, the proportion of methoxy endgroups was $\sim 60 \%-70 \%$. For practical reasons we choose to only model chains with one chlorine and one methoxy endgroup $\left(\mathrm{Cl}-\{\text { monomer }\}_{n}-\mathrm{OCH}_{3}\right)$.

In a first step, polysulfone chains are generated by PMC-MD single-chain sampling at temperatures corresponding to melt conditions (550 K for PESU and PPSU, and $500 \mathrm{~K}$ for PSU), i.e., slightly above their experimental glass transition temperature ( $\sim 497 \mathrm{~K}$ for PESU ${ }^{15,63,199-207}$ and PPSU, ${ }^{201,204,208}$ and $\sim 459 \mathrm{~K}$ for PSU. ${ }^{9,15,16,63,163,199,204-212}$ Then, in a second step, 20 uncorrelated chains are randomly reorientated and distributed in a periodic cubic MD box at an initial density close to the experimental values which are $\sim 1.37 \pm$ $0.01 \mathrm{~g} \mathrm{~cm}^{-3}$ for PESU, ${ }^{197,199,201,204,206,207} \sim 1.291 \pm 0.001 \mathrm{~g}$ $\mathrm{cm}^{-3}$ for PPSU, ${ }^{204,209}$ and $\sim 1.238 \pm 0.001 \mathrm{~g} \mathrm{~cm}^{-3}$ for PSU. ${ }^{9,29,197,204,206,207,209-215}$ To avoid unphysical spearings and interlockings ${ }^{216}$ during the introduction of excluded volume, a «phantom » atom is briefly placed at the centre of mass of each six-atom ring. ${ }^{175}$ The "bonded potentials" are then switched on progressively during short MD simulations under constant volume and temperature conditions (NVT). Phantom atoms are then removed, and electrostatic interactions are switched on. Details of the three systems and the nonbonded parameters used in each are reported in Table 1.

Following the introduction of the excluded volume, the systems were then relaxed under NVT conditions at $550 \mathrm{~K}$ (for PESU and PPSU) or $500 \mathrm{~K}$ (for PSU) until thermal equilibrium was established. The bulk systems were then cooled to $300 \mathrm{~K}$ at a rate of $-1 \mathrm{~K} \mathrm{ps}^{-1}$, relaxed for $100 \mathrm{ps}$ at NVT, before being further relaxed at constant pressure (NPT) conditions. In these, latter NPT simulations the on-diagonal and off-diagonal components of the required pressure tensor $\mathbf{P}$ were set to 1 and 0 bar, respectively. Once the densities and energies stabilized, production runs were carried out over $\sim 5000$ ps at both $300 \mathrm{~K}$ and $373 \mathrm{~K}$. Configurations were stored every 5 ps for postanalysis. Simulations were performed on the EDF "Rendvous" cluster with the parallel version, ddgmq, of the gmq program, on 27 CPUs. Parallel efficiency, i.e., the ratio of CPU time to wall time, was very high at $99.94 \%$.

\section{Validation of the Dry Polysulfone Models}

Average pressures in the production simulations were all close to the target pressure at $1 \pm 1$ bar. The corresponding average densities for the dry polysulfone systems at 300 and $373 \mathrm{~K}$ are given in Table 2.

In comparison, the averages of experimental densities found in the literature are $\sim 1370 \pm 10 \mathrm{~kg} \mathrm{~m}^{-3}$ for PESU, ${ }^{197,199,201,204,206,207} \sim 1291 \pm 1 \mathrm{~kg} \mathrm{~m}^{-3}$ for PPSU, ${ }^{204,209}$ and $\sim 1238 \pm 1 \mathrm{~kg} \mathrm{~m}^{-3}$ for PSU. ${ }^{9,29,197,204,206,207,209-215}$ Relative differences between model densities at $300 \mathrm{~K}$ (Table 2) and experimental densities are about $1.6 \%$ for PESU, $1.7 \%$ for PPSU and $0.7 \%$ for PSU, which is reasonably satisfactory if we compare with previous work which reported differences of $\sim 5 \%$ and $2.7 \%$ for PESU models, ${ }^{113,162}$ and $\sim 3 \%$ for PSU models. ${ }^{162-164}$ Use of hydrogens as end groups, ${ }^{113}$ or possibly other end groups (such information is not always given) could be one reason for these differences, as could the different chain lengths used: 60 PESU monomers for Ahn 
TABLE 2 Relaxed Densities $\langle\boldsymbol{\rho}\rangle$ Average Potential (pot), Polymer-Polymer (pol-pol), Polymer-Water (pol-wat), and Water-Water (wat-wat) Potential Energies for the Dry and the Hydrated PESU, PPSU, and PSU Models

\begin{tabular}{|c|c|c|c|c|c|c|c|c|c|c|c|c|}
\hline System & $\begin{array}{c}\langle\rho\rangle \\
\left(\mathrm{kg} \mathrm{m}^{-3}\right)\end{array}$ & $U_{\text {pot }}^{\text {inter }}$ & $U_{\text {pol }}^{\text {intra }}$ & $U_{\text {pol-pol }}^{\text {inter }}$ & $U_{\text {pol-pol }}^{\text {inter } L J}$ & $U_{\text {pol-pol }}^{\text {inter Coul }}$ & $U_{\text {pol-wat }}^{\text {total }}$ & $U_{\text {pol-wat }}^{L J}$ & $U_{\text {pol-wat }}^{\text {Coul }}$ & $U_{\text {wat-wat }}^{\text {total }}$ & $U_{\text {wat-wat }}^{L J}$ & $U_{\text {wat-wat }}^{\text {Coul }}$ \\
\hline PESU $300 \mathrm{~K}$ & 1391.9 & -69.5 & 37.2 & -69.5 & -58.0 & -11.5 & & & & & & \\
\hline PESU $373 \mathrm{~K}$ & 1376.7 & -67.7 & 49.9 & -67.7 & -56.5 & -11.2 & & & & & & \\
\hline PESU 1:8 & 1384.4 & -73.9 & 49.6 & -66.9 & -56.2 & -10.7 & -6.1 & -0.6 & -5.5 & -0.9 & 0.28 & -1.2 \\
\hline PESU 1:4 & 1388.8 & -80.2 & 49.6 & -66.3 & -56.0 & -10.4 & -11.2 & -1.2 & -10.0 & -2.7 & 0.74 & -3.4 \\
\hline PESU 1:2 & 1397.3 & -92.6 & 49.4 & -65.1 & -55.2 & -9.9 & -20.1 & -2.6 & -17.5 & -7.4 & 2.03 & -9.4 \\
\hline PPSU $300 \mathrm{~K}$ & 1313.2 & -123.8 & 3.7 & -123.8 & -112.3 & -11.5 & & & & & & \\
\hline PPSU $373 \mathrm{~K}$ & 1295.8 & -120.5 & 27.4 & -120.5 & -109.3 & -11.2 & & & & & & \\
\hline PPSU 1:8 & 1301.4 & -126.6 & 27.6 & -120.2 & -109.2 & -10.9 & -5.6 & -0.6 & -5.0 & -0.9 & 0.24 & -1.1 \\
\hline PPSU 1:4 & 1304.9 & -132.4 & 27.1 & -119.6 & -108.8 & -10.8 & -10.1 & -1.3 & -8.8 & -2.7 & 0.74 & -3.5 \\
\hline PPSU 1:2 & 1310.9 & -144.1 & 26.8 & -118.3 & -108.1 & -10.3 & -18.8 & -2.8 & -16.0 & -6.9 & 1.86 & -8.8 \\
\hline PSU $300 \mathrm{~K}$ & 1229.8 & -124.5 & -45.2 & -124.5 & -113.5 & -11.0 & & & & & & \\
\hline PSU $373 \mathrm{~K}$ & 1203.5 & -120.1 & -17.3 & -120.1 & -109.1 & -11.0 & & & & & & \\
\hline PSU 1:8 & 1207.7 & -125.9 & -17.6 & -119.6 & -109.1 & -10.6 & -5.6 & -0.6 & -5.0 & -0.7 & 0.20 & -0.9 \\
\hline PSU sat & 1208.0 & -128.0 & -17.8 & -119.2 & -108.8 & -10.4 & -7.5 & -0.8 & -6.7 & -1.3 & 0.34 & -1.6 \\
\hline PSU 1:4 & 1211.7 & -131.8 & -17.7 & -119.1 & -108.8 & -10.2 & -10.3 & -1.3 & -9.0 & -2.4 & 0.65 & -3.0 \\
\hline PSU 1:2 & 1216.4 & -143.4 & -17.7 & -118.0 & -108.3 & -9.8 & -19.3 & -2.7 & -16.6 & -6.1 & 1.64 & -7.7 \\
\hline Max. error & 0.8 & 0.2 & 0.2 & 0.1 & 0.1 & 0.1 & 0.3 & 0.2 & 0.3 & 0.1 & 0.02 & 0.1 \\
\hline
\end{tabular}

Total $U^{\text {total }}$, intramolecular $U^{\text {intra }}$, and intermolecular $U^{\text {inter }}$ energies are reported along with the specified Van der Waals $U^{L J}$ and Coulombic $U^{\text {Coul }}$ contributions in $\mathrm{kJ} \mathrm{mol}^{-1}$ of monomer.

et al., ${ }^{113} 210$ PESU monomers for Heuchel et al., ${ }^{162} 94$ PSU monomers for Hölck et al. ${ }^{163,164}$ and 210 for Heuchel et al. ${ }^{162}$ The influence of the generation procedure can also be a factor.

By applying average experimental linear expansion coefficients $\left(\alpha_{l}^{T \rightarrow T_{0}}\right)$, determined in the range of $300-373 \mathrm{~K}$, to the average experimental densities of PESU, PPSU, and PSU, we can have a good approximation to their experimental densities at $373 \mathrm{~K}\left(\rho_{\exp }^{373 \mathrm{~K}}\right)$ :

$$
\rho^{T}=\rho^{T_{0}}\left[1-3 \alpha_{l}^{T \rightarrow T_{0}}\left(T-T_{0}\right)\right]
$$

where $\rho^{T}$ and $\rho^{T_{0}}$ are the polymer densities at the temperatures $T$ and $T_{0}$ (in $\mathrm{kg} \mathrm{m}^{-3}$ ) and $\alpha_{l}^{T \rightarrow T_{0}}$ is the linear expansion coefficient of the polymer between $T$ and $T_{0}$ (in $\mathrm{K}^{-1}$ )

Between 300 and $373 \mathrm{~K}$, average experimental linear expansion coefficients found in the literature are $\sim 5.3 \times 10^{-5} \mathrm{~K}^{-1}$ for PESU, ${ }^{42,204} \sim 5.5 \times 10^{-5} \mathrm{~K}^{-1}$ for PPSU, ${ }^{204} \sim 5.1 \times 10^{-5}$ $\mathrm{K}^{-1}$ for PSU. ${ }^{204}$ We can thus estimate $\rho_{\exp }^{\text {PESU37K }} \sim 1354 \mathrm{~kg}$ $\mathrm{m}^{-3}, \rho_{\exp }^{\text {PPSU373K }} \sim 1275 \mathrm{~kg} \mathrm{~m}^{-3}$ and $\rho_{\exp }^{\text {PSU37K }} \sim 1224 \mathrm{~kg} \mathrm{~m}^{-3}$. These differ by $\sim 1.7 \%, \sim 1.6 \%$, and $\sim 1.7 \%$, respectively, from our model densities of PESU, PPSU, and PSU at $373 \mathrm{~K}$ (Table 2).

The average total intermolecular potential energies $\left\langle U_{\text {pot }}^{\text {inter }}\right\rangle$, also given in Table 2, are due mostly to Van der Waals interactions ( $\sim 83 \%$ for PESU and $\sim 90 \%$ for PPSU and PSU). This trend has already been seen in polyimides. ${ }^{156,171,176}$ Hilde- brand solubility parameters of the models $\delta_{\text {model }}^{300 \mathrm{~K}}$ have also been calculated at $300 \mathrm{~K}$ by using the following equation:

$$
\delta=\sqrt{\frac{\left\langle U_{\text {pot }}^{\text {inter }}\right\rangle}{\langle V\rangle}}
$$

We have found: $\delta_{\text {PESU model }}^{300 \mathrm{~K}}=20.4\left(\mathrm{~J} \mathrm{~cm}^{-3}\right)^{1 / 2}, \delta_{\text {PPSU model }}^{300 \mathrm{~K}}=$ $20.1\left(\mathrm{~J} \mathrm{~cm}^{-3}\right)^{1 / 2}, \delta_{\text {PSU model }}^{300 \mathrm{~K}}=18.6\left(\mathrm{~J} \mathrm{~cm}^{-3}\right)^{1 / 2}$. Rigorously, Hildebrand solubility parameters can only be experimentally determined on vaporizable molecules, which is not the case of our polymers. However, experimental techniques based on the wave propagation velocity of ultrasonic sounds in polymers, ${ }^{217}$ or on viscosity measurements have also been used, $^{218}$ even if authors themselves warn strongly about the accuracy of their data. Empirical techniques to evaluate Hildebrand solubility parameters ${ }^{111}$ can also be used but are rarely satisfactory, and the discrepancy of their results on a same polymer has already been shown. ${ }^{219}$ Thus, empirical and experimental values reported by a same author using different techniques are found to vary between 21.3 and $28\left(\mathrm{~J} \mathrm{~cm}^{-3}\right)^{1 / 2}$ for PESU, ${ }^{217}$ and between 17.38 and 21.79 $\left(\mathrm{J} \mathrm{cm}^{-3}\right)^{1 / 2}$ for PSU. ${ }^{218}$ Using the increments given by Matsuura et al., ${ }^{220}$ we can also evaluate $\delta_{\mathrm{PESU}}^{300 \mathrm{~K}}=22.3\left(\mathrm{~J} \mathrm{~cm}^{-3}\right)^{1 / 2}$, $\delta_{\mathrm{PPSU}}^{300 \mathrm{~K}}=21.6\left(\mathrm{~J} \mathrm{~cm}^{-3}\right)^{1 / 2}$, and $\delta_{\mathrm{PSU}}^{300 \mathrm{~K}}=20.3\left(\mathrm{~J} \mathrm{~cm}^{-3}\right)^{1 / 2}$. If the different methods lead to different values of the solubility parameter for the same polymer, we can see that our models agree favorably well with the trend $\delta_{\mathrm{PESU}}>\delta_{\mathrm{PPSU}}>\delta_{\mathrm{PSU}}$. 
The fractional free volume, FFV, in the dry models can be empirically calculated using the following equation:

$$
\mathrm{FFV}=\frac{V-V_{0}}{V}
$$

where $V$ is the actual volume and $V_{0}$ is the zero point molar volume. $V_{0}$ was taken as being 1.3 times the Van der Waals volume $V_{w}$ of the polysulfone monomer calculated by a group contribution method $\left(V_{\mathrm{w}}^{\mathrm{PESU}}=111.9 \mathrm{~cm}^{3} \mathrm{~mol}^{-1}\right.$ of monomer; $V_{\mathrm{w}}^{\text {PPSU }}=203.5 \mathrm{~cm}^{3} \mathrm{~mol}^{-1}$ of monomer; $V_{\mathrm{w}}^{\mathrm{PSU}}=$ $234.2 \mathrm{~cm}^{3} \mathrm{~mol}^{-1}$ of monomer). ${ }^{111,221}$ We have so calculated FFV values for our models at $300 \mathrm{~K}$ : $\mathrm{FFV}_{\text {model }}^{\mathrm{PESU} 300 \mathrm{~K}}=0.130$, $\mathrm{FFV}_{\text {model }}^{\mathrm{PPS} 300 \mathrm{~K}}=0.135, \mathrm{FFV}_{\text {model }}^{\text {PSU300K }}=0.156$. FFV values for polysulfones under study have been reported in the literature. ${ }^{9,15,16,63,200,201,209-212}$ Nevertheless, the values used for $V_{\mathrm{w}}$ are not always clearly stated. We can calculate the experimental FFV from the average densities previously shown by using the same $V_{\mathrm{w}}$ values than those used with our models. In this case, FFV is calculated by:

$$
\mathrm{FFV}=\frac{\frac{M}{\rho}-V_{0}}{\frac{M}{\rho}}
$$

where $M$ is the molar mass of one mole of monomer (in $\mathrm{g} \mathrm{mol}^{-1}$ of monomer) and $\rho$ is the average experimental density of the polymer (in $\mathrm{g} \mathrm{cm}^{-3}$ ). So, with $M_{\mathrm{PESU}}=232 \mathrm{~g} \mathrm{~mol}^{-1}$ of monomer, $M_{\mathrm{PPSU}}=400 \mathrm{~g} \mathrm{~mol}^{-1}$ of monomer, $M_{\mathrm{PSU}}=$ $442 \mathrm{~g} \mathrm{~mol}^{-1}$ of monomer, we obtain $\mathrm{FFV}_{\text {exp }}^{\text {PESU300K }} \sim 0.141$, $\mathrm{FFV}_{\text {exp }}^{\mathrm{PPS} 300 \mathrm{~K}} \sim 0.146, \mathrm{FFV}_{\exp }^{\mathrm{PSU} 300 \mathrm{~K}} \sim 0.147$, which compare quite well with our model values.

As far as the structures of the polysulfones under study are concerned, the indiscriminate intermolecular radial distribution functions for the chains $g_{\text {inter }}(r)$ do not show any sign of crystallinity, which is in agreement with the well-known amorphous nature of polysulfones. ${ }^{42,163,202,204,209,222,223}$ Experimental studies of the structure of these polysulfones are available in the form of X-ray diffraction patterns, see for example Figure 1 of Khayet and Garcia-Payo ${ }^{224}$ for PESU and Figure 8 of Aitken et al. ${ }^{209}$ for PPSU and PSU (labeled BIPSF and PSF, respectively, in their figure). In an attempt to make comparisons with experimental data, pseudo X-ray powder diffractograms (Debye formula) were generated using the DISCUS program. ${ }^{225}$ Diffractograms were obtained from the coordinates of configurations separated by 100 ps over the last 1 ns of the production runs of the pure polysulphones at $300 \mathrm{~K}$. The average diffractograms for each polysulfone are shown in Figure 3.

The X-ray wavelength used in the calculations was $\lambda=1.54$ $\AA$, corresponding to that of $\mathrm{Cu} \mathrm{K}_{\alpha}$ radiation used in the experiments. All three model polysulphones show a single broad peak centered in the region from $\sim 16^{\circ}$ to $\sim 18^{\circ}$ in broad agreement with experimental studies. ${ }^{209,224,226,227}$

Figure 4 shows the average distributions of pivot torsion angles in the dry PESU, PPSU and PSU from the simulations at $300 \mathrm{~K}$. The $\mathrm{C}-\mathrm{C}-\mathrm{S}-\mathrm{C}$ pivot torsion angle has a bimodal distribution at $\pm 90^{\circ}$ and the $\mathrm{C}-\mathrm{C}-\mathrm{C}-\mathrm{C}$ angle shows favored

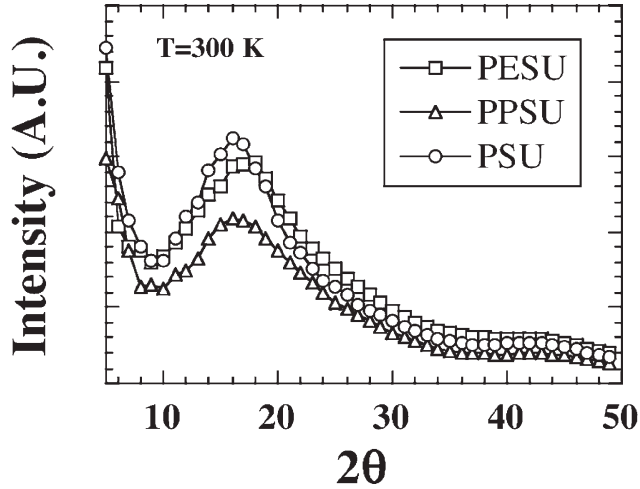

FIGURE 3 Pseudo X-ray diffractograms for the three pure polysulfones at $300 \mathrm{~K}$.

positions at $\pm 127^{\circ}$ and $\pm 44^{\circ}$, in agreement with previous simulation results. ${ }^{159,160}$ The distribution of $\mathrm{C}-\mathrm{C}-\mathrm{O}-\mathrm{C}$ angles shows maxima at $\pm 138^{\circ}$ and $\pm 44^{\circ}$, which agrees with the results of Niemela et al., ${ }^{160}$ whereas Hamerton et al. ${ }^{159}$ find a broader bimodal distribution at $\pm 90^{\circ}$, which is not incompatible with our more resolved distributions.

To characterize the actual void space in the models, we use a version of the widely encountered "phantom sphere" geometric technique..$^{216,228-231}$ Full details can be found elsewhere $^{190}$ but in this technique the probe accessible volume (PAV) is obtained by trial insertions of a virtual probe of a given radius at random positions in the polymer configurations. Probe insertions are then labeled "accepted" or "rejected" according to whether the probe overlaps with any of the atoms in the system; atoms being considered as hard spheres for this purpose with the following radii: $\mathrm{C}=1.70$ $\AA, O=1.52 \AA, S=1.80 \AA, H=1.20 \AA$. The PAV is then defined as the product of the total volume and the fraction of "accepted" insertions. As such, the PAV gives just that part of the volume accessible to the centers of the probes. It does not give the actual volume that the entire probe can access. The PAV is just a simple way to compare different model systems under the same conditions.

The probe radii leading to a PAV equal to the $\mathrm{FFV}_{\exp }^{300 \mathrm{~K}}$ previously determined, is $0.34 \AA$ for PESU and PPSU, and $0.37 \AA$ for PSU, whereas it has been found equal to $0.4 \AA$ by Heuchel et al. for PESU and PSU. ${ }^{162}$ We can explain these differences by the lower densities of their PESU and PSU systems, by the possible use of different reference values for the FFV, and also by the use of slightly inferior radii for atoms of the polymer. Nevertheless, to a first approximation, the values are in reasonable agreement.

The qualitative distribution of the PAV was obtained by analyzing the connectivity of the positions of accepted probe insertions. Effectively two accepted probes are considered to be "linked," i.e., in the same hole, if the distance between their centers is less than some arbitrary distance. Hole sizes are then obtained from a standard cluster analysis of the interconnected centers. As already said, this analysis can not be interpreted in terms of actual volume accessible and can 

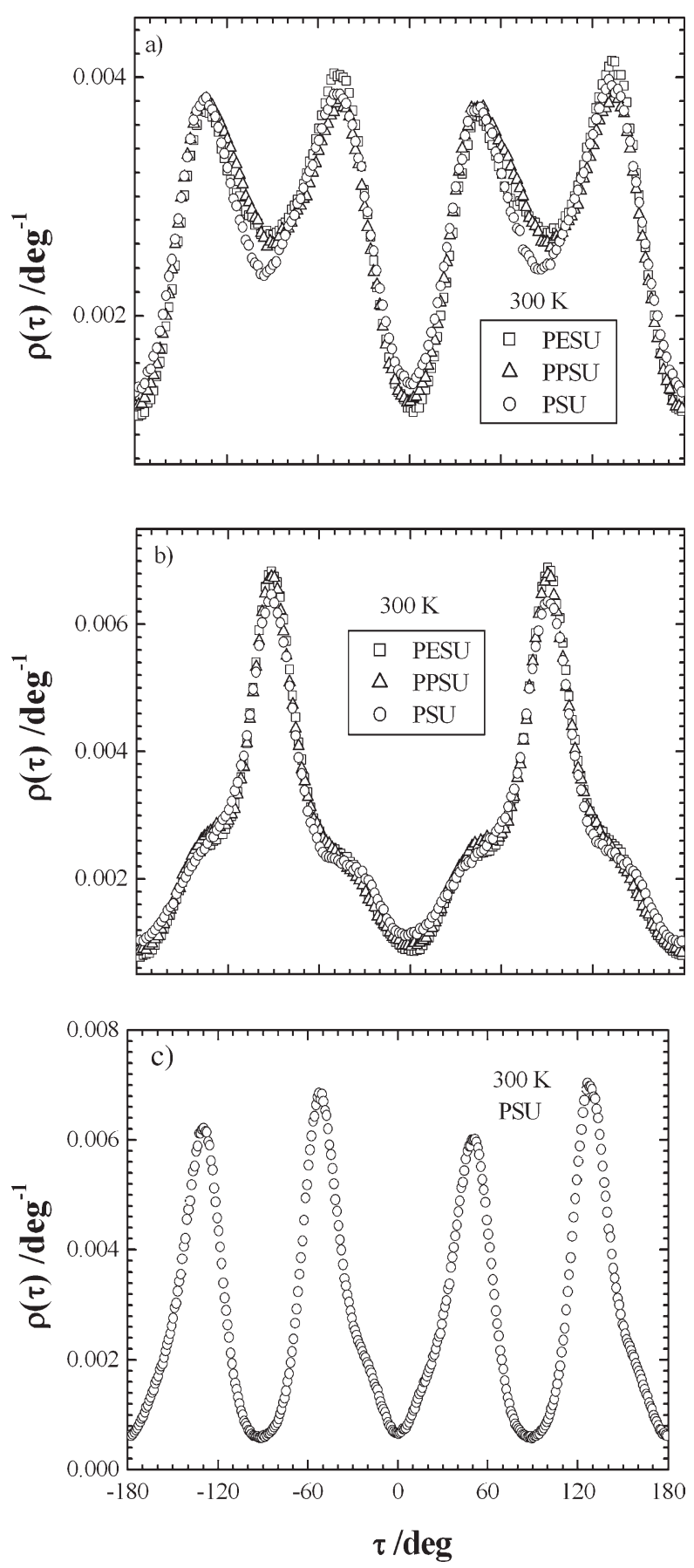

FIGURE 4 Probability densities for the (a) $\mathrm{C}-\mathrm{C}-\mathrm{O}-\mathrm{C}$, (b) $\mathrm{C}-\mathrm{C}-\mathrm{S}-\mathrm{C}$, and (c) $\mathrm{C}-\mathrm{C}-\mathrm{C}-\mathrm{C}$ pivot torsion angles in the dry systems of PESU, PPSU, and PSU at $300 \mathrm{~K}$.

just be used to compare different models under same conditions. No attempt to compare with experimental ${ }^{232}$ or simulation $^{161,162}$ results concerning the average cavity size in polysulfones will thus be done. Using a probe radius of $1.6 \AA$, with a cutoff distance linking the probe centers of $0.5 \AA$, leads to a distribution of void volumes which can be compared between the systems. All subsequent analyses will be done with these parameters. Moreover, $1.6 \AA$ corresponds to the Van der Waals radius of a water molecule if we consider a spherical geometry. Figure 5 shows the distribution of the amount of PAV, normalized by the total volume $\left(V_{\text {total }}\right)$, in the polymer matrices in holes of different sizes for the PESU, the PPSU and the PSU at 300 and $373 \mathrm{~K}$. The distributions have been averaged over all configurations stored during the 5 ns production runs.

Figure 5 shows a monotically decreasing amount of PAV is to be found in holes of increasing size. There is no sign of cavitation, i.e., large holes, for any of the polysulfones considered. Increasing temperature gives rise to a fairly homogeneous increase in the PAV as the densities drop with temperature. The PAV in PSU is more important than in PESU or PPSU, which is consistent with our model values of FFV. The areas, $\Omega$, under the curves displayed in Figure 5 give the total proportion of the volume of the polymer which is accessible to the center of a spherical probe of radius 1.6 $\AA$, that is to say, accessible to the center of a probe of the same volume than the Van der Waals volume of a water molecule. The average values found were: $\Omega_{\mathrm{PESU}}^{300 \mathrm{~K}}=0.00093$, $\Omega_{\mathrm{PPSU}}^{300 \mathrm{~K}}=0.00086, \Omega_{\mathrm{PSU}}^{300 \mathrm{~K}}=0.00127, \Omega_{\mathrm{PESU}}^{373 \mathrm{~K}}=0.00123, \Omega_{\mathrm{PPSU}}^{373 \mathrm{~K}}$ $=0.00137, \Omega_{\mathrm{PSU}}^{373 \mathrm{~K}}=0.00202, \Omega_{\mathrm{PMDA}-\mathrm{ODA}}^{373 \mathrm{~K}}=0.006$. As water solubility in PESU is about 2 times higher than those in the PPSU and in the PSU, this is an indication that the volume "accessible" to a water molecule does not govern alone the water uptake. In comparison to the polysulfones the PAV in PMDA-ODA at the same temperature is considerably higher and larger holes are present. This is consistent with its capacity to absorb more water and, as we will see, explains differences in the water clustering behavior.

\section{HYDRATED POLYSULFONES}

\section{Water Insertion}

The procedure of water insertion is the same as has been explained in a previous article. ${ }^{156}$ In brief, to avoid large

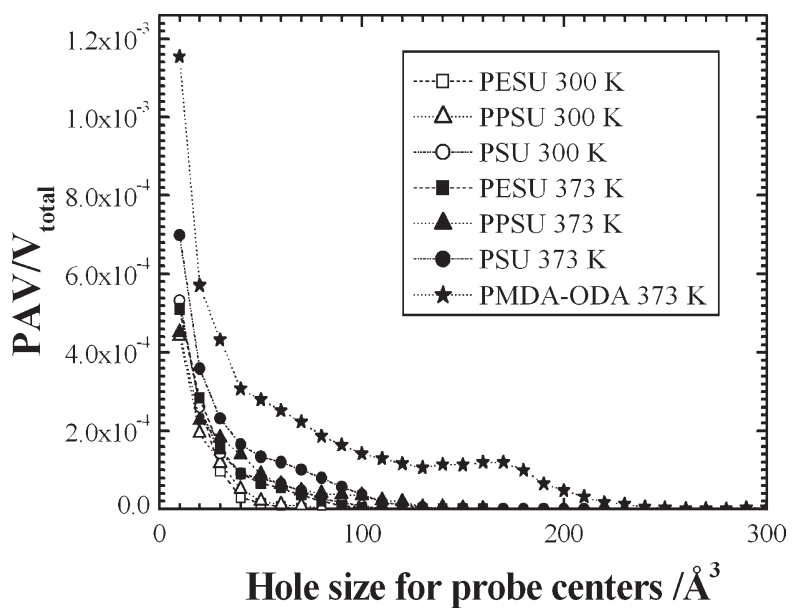

FIGURE 5 Distribution of the amount of probe accessible volume in holes of different sizes. Data are normalized by the total volume of the respective MD simulation boxes and averaged over all configurations of the dry PESU, PPSU, and PSU systems at 300 and $373 \mathrm{~K}$. For comparison, we include the results obtained from our previous simulation of PMDA-ODA ${ }^{156}$ using the same probe size and at $373 \mathrm{~K}$ also. 
overlaps and spearing of aromatic rings, an equilibrated simulation box of SPC/E water $\left(\rho=958 \mathrm{~kg} \mathrm{~m}^{-3}, T=373 \mathrm{~K}\right)$, of the same size than the preprepared dry polymer one, is superimposed over the dry polymer one and the water molecules to insert are chosen amongst those which overlap least with the polymer atoms. Only a small number of steps of energy minimization are then required to remove any slight overlaps. The hydrated systems were then simulated using MD under NPT conditions at $373 \mathrm{~K}$ and 1 bar for 5100 ps. As for PMDA-ODA, ${ }^{156}$ an elevated temperature was required to provide sufficient mobility of the water molecules to consider the time of the simulation sufficient for the study of the structural properties of water in the polymer matrices. The Ewald sum parameters and Van der Waals potential truncation radii were the same than those used for the dry systems (see Table 1).

We point out that the initial configurations chosen for the insertion of water were those at the start of the production runs of the dry systems. In this way, the dry and hydrated production runs can be considered as being carried out parallel in time and thus any underlying differences due to the slow relaxation of the polymer matrices are minimized.

The actual choice for the amounts of water to insert was based on experimental results. The average water content at saturation, $w_{\infty}$ is defined to be the weight percentage of water uptake by polymers exposed to an environment of $100 \%$ relative humidity $(100 \% \mathrm{RH})$,

$$
w_{\infty}=\frac{m_{\text {water }}}{m_{\text {dry polymer }}}
$$

where $m_{\text {water }}$ is the mass of water into the polymer and $m_{\text {dry polymer }}$ is the mass of the dry polymer. Experimentally determined values of $w_{\infty}$ in the range from 20 to $50{ }^{\circ} \mathrm{C}$, have been found to be 2 wt $\%$ for PESU, ${ }^{15,42,64,199,200,204,233} 1.1$ wt \% for PPSU, ${ }^{64,204}$ and 0.7 wt $\%$ for PSU. ${ }^{9,15,16,29,64,199,204,213,233}$ In addition, the hydrophilic behavior of the polysulfones is generally attributed to their sulfonic groups $\left(\mathrm{SO}_{2}\right){ }^{64,108}$ For this reason, we have chosen to simulate systems with different ratios of water molecules per sulfonic group $\left(n_{\mathrm{H}_{2} \mathrm{O}}: n_{\mathrm{SO}_{2}}\right)$ spanning the range up to and beyond experimental saturation. System names are defined from the polymer matrix and the $n_{\mathrm{H}_{2} \mathrm{O}}: n_{\mathrm{SO}_{2}}$ ratio. In other words, the system "PESU $1: 2$ " is a poly(ether sulfone) with a ratio $n_{\mathrm{H}_{2} \mathrm{O}}: n_{\mathrm{SO}_{2}}=1: 2$. Details of systems simulated are given in Table 3.

Experimentally estimates of the heats of dissolution of water in polymers are often obtained by first measuring the equilibrium uptake of water at a range of temperatures. Fitting the data to an Arrhenius law then gives an activation energy which is considered to be approximately $\Delta H_{\text {mixing }}=$ $\Delta H_{\mathrm{s}}+\Delta H_{\mathrm{v}}{ }^{51,77}$ where $\Delta H_{\text {mixing }}$ is the mixing enthalpy of liquid water in the polymer, $\Delta H_{\mathrm{s}}$ is the heat of dissolution of water vapor in the polymer and $\Delta H_{\mathrm{v}}$ is the heat of vaporization of liquid water. From the known values of the heat of
TABLE 3 The numbers of Water Molecules, Corresponding $\mathrm{H}_{2} \mathrm{O}$ Weight Percentages (eq 7), and Total Number of Atoms in the Dry and Hydrated Systems

\begin{tabular}{llrll}
\hline Polymer & System & $n_{\mathrm{H}_{2} \mathrm{O}}$ & $\begin{array}{l}\text { Wt } \% \\
\text { of } \mathrm{H}_{2} \mathrm{O}\end{array}$ & $\begin{array}{l}\text { Number } \\
\text { of Atoms }\end{array}$ \\
PESU & Dry & 0 & 0 & 48,100 \\
& PESU 1:8 & 250 & 0.97 & 48,850 \\
& PESU 1:4 & 500 & 1.93 & 49,600 \\
\hline \multirow{3}{*}{ PPSU } & PESU 1:2 & 1000 & 3.87 & 51,100 \\
& Dry & 0 & 0 & 45,100 \\
\hline \multirow{2}{*}{ PSU } & PPSU 1:8 & 125 & 0.56 & 45,475 \\
& PPSU 1:4 & 250 & 1.12 & 45,850 \\
& PPSU 1:2 & 500 & 2.24 & 46,600 \\
& Dry & 0 & 0 & 54,100 \\
& PSU 1:8 & 125 & 0.51 & 54,475 \\
& PSU sat & 172 & 0.70 & 54,616 \\
\hline & PSU 1:4 & 250 & 1.02 & 54,850 \\
\hline & PSU 1:2 & 500 & 2.03 & 55,600 \\
\hline
\end{tabular}

vaporization of water, indirect estimates of $\Delta H_{\mathrm{s}}$ can then be obtained. For the polysulfones under study the averages of such available experimental estimates are $\Delta H_{\mathrm{S}}^{\mathrm{PESU}}=-43 \pm$ $2 \mathrm{~kJ} \mathrm{~mol}{ }^{-1}, \Delta H_{\mathrm{S}}^{\mathrm{PPS}}=-42 \pm 4 \mathrm{~kJ} \mathrm{~mol}^{-1}$ and $\Delta H_{\mathrm{S}}^{\mathrm{PSU}}=-37$ $\pm 2 \mathrm{~kJ} \mathrm{~mol}^{-1}$.64,108,187,217 These values suggest a weak temperature dependence of the water content at saturation, $w_{\infty}(T)$, due to the fact that the decrease of water solubility with temperature is almost entirely compensated by the increase of the saturated vapor pressure of water ${ }^{64,108-110}$ Experimental measurements of the water content at saturation in these polysulfones at $373 \mathrm{~K}$ and $100 \% \mathrm{RH}\left(w_{\infty}^{373 \mathrm{~K}}\right)$ tend to confirm this hypothesis $\left(w_{\infty}^{\text {PESU373K }}=2.0 \pm 0.1\right.$ wt $\% ;{ }^{187,202,217} w_{\infty}^{\text {PPSU 373K }} \sim$ 1.2 wt $\% ;^{187} w_{\infty}^{\text {PSU } 373 \mathrm{~K}}=0.9 \pm 0.1$ wt $\left.\%{ }^{187,217}\right)$.

\section{Volumetric and Energetic Properties}

Figure 6 shows the relative variations of the volumes $\Delta V /$ $V_{\text {dry }}=\left(V_{\text {hydrated }}-V_{\text {dry }}\right) / V_{\text {dry }}$ at $373 \mathrm{~K}$ as a function of the water content for all three polysulfone systems. Experimental data obtained at ambient temperatures are also given for comparison in spite of the difference in temperature. Our experimental data were obtained using films of Radel R 5000 CL301 (PPSU) of thickness $e=100 \mu \mathrm{m}$, films of Radel A-200 (PESU), and films of Udel P-1700 NT-11 (PSU), both with $e$ $=125 \mu \mathrm{m}$, provided by Solvay Advanced Polymers. Samples of $\sim 9 \mathrm{~cm}^{2}$ were exposed to different relative humidity controlled environments as obtained above various saturated salt solutions:- $\mathrm{MgCl}_{2}, 6 \mathrm{H}_{2} \mathrm{O} \approx 33 \% \mathrm{RH}, \mathrm{Ca}\left(\mathrm{NO}_{3}\right)_{2}, 4 \mathrm{H}_{2} \mathrm{O} \approx$ $55 \% \mathrm{RH}, \mathrm{NaCl} \approx 76 \% \mathrm{RH}$, and $\mathrm{ZnSO}_{4}, 7 \mathrm{H}_{2} \mathrm{O} \approx 90 \% \mathrm{RH}^{234-236}$ Densities have been experimentally determined by flotation in heptane-carbon tetrachloride mixtures at $297 \mathrm{~K}$ with solvents of analytical grade just after the withdrawal of the equilibrated samples of their RH controlled environment to avoid water loss. Volume expansions are then obtained from the experimental density measurements using the following expression 


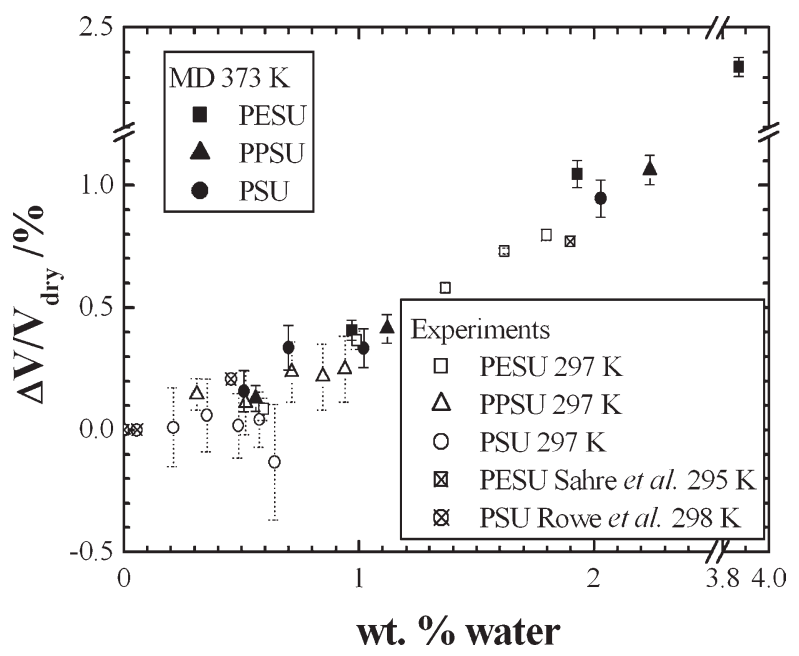

FIGURE 6 Average relative variations, $\Delta V / V_{\text {dry }}=\left(V_{\text {hydrated }}-V_{\text {dry }}\right) /$ $V_{\text {dry, }}$ of the simulated PESU, PPSU, and PSU systems plotted as a function of the water content at $373 \mathrm{~K}$. Average experimental data obtained from density measurements and eq 8 at $297 \mathrm{~K}$ are reported with their standard errors. Experimental data taken from the literature are also displayed. ${ }^{29,30}$

$$
\frac{\Delta V}{V_{\text {dry }}}=(1+w) \frac{\rho_{\text {dry }}}{\rho_{\text {wet }}}-1
$$

where $\rho_{\text {dry }}$ is the density of the dry polymer, $\rho_{\text {wet }}$ is the density of the hydrated polymer and $w$ is the weight water content ( $w=m_{\text {water }} / m_{\text {dry }}$ polymer $)$. Three measurements have been made for each sample and each RH.

Other experimental values from the literature are also shown in Figure 6. They are obtained from linear expansion coefficients, $\beta_{\mathrm{l}}$, of the thickness of polymer films as measured by ellipsometry. ${ }^{29,30}$ Rowe et al. showed for their films that expansions in the transverse directions are negligible. ${ }^{29}$ Thus we can, to a first approximation, consider $\beta_{1}$ as being equal to the volume expansion coefficient.

In Figure 6, it appears that our models reproduce quite well the swelling behavior of the tested polysulfones. For water contents below and above the experimental saturation values, we observe volume expansions in the models. A global linear regression of all the data points suggests that the expansion could be zero up to $\sim 0.3$ wt $\%$. A comparison can be made here with our previously published results for a model PMDA-ODA system, which did not show any swelling below the much higher value of $\sim 3$ wt $\%$ of water. ${ }^{156} \mathrm{We}$ had interpreted this as being due to a hole filling mechanism of water molecules being preponderant at water contents inferior to $\sim 3$ wt $\%$; a result consistent with the comparison shown for the probe accessible volumes in Figure 5. At the time the available experimental data for PMDA-ODA was rather inconclusive with volume swelling at high $\mathrm{RH}$ varying from as much as $2.5 \%$ down to negligible values. ${ }^{24,31,34,237}$ Since then we have carried out our own experimental tests on PMDA-ODA (using Kapton ${ }^{\circledR}$ film) in the same manner as described above for the polysulfones. These new measurements show a fairly linear amount of swelling in PMDA-ODA up to $\sim 1.5 \%$ at saturation $(\sim 2.5 \mathrm{wt} \%$ of water $){ }^{187}$ It is interesting to note also that the swelling in this family of polysulfones is very similar despite their different hydrophilicities.

From these volume expansions, we can calculate the partial molar volume of one water molecule $(\delta V)$ as a function of the water content in these polysulfones by using:

$$
\delta V=\frac{\Delta V}{n_{\mathrm{H}_{2} \mathrm{O}}}
$$

Figure 7 shows the partial molar volumes of $\mathrm{H}_{2} \mathrm{O}(\delta V)$ as a function of the water content in the hydrated PESU, PPSU, and PSU models.

We can see that the partial molar volume of the water in these polysulfones generally increases with water content. Near experimental saturation, $\delta V$ in PESU and PSU is $\sim 12 \AA^{3}$ and $\delta V \sim 8 \AA^{3}$ in PPSU. As was the case for PMDA-ODA, ${ }^{156}$ these values are well below the partial molar volume of liquid water $\left(\sim 30 \AA^{3}\right)$, and even below the Van der Waals volume of a water molecule $\left(\sim 17 \AA^{3}\right)$. This is in agreement with the usual observation that hydrated polymers are far from ideal solutions at low water content. ${ }^{11,25,26}$ Tests of the swelling data using various empirical models shows that one based on the assumption of constant capacity, i.e., the ratio of Van der Waals to total volume, but incorporating a term to account for the "volume contraction" provided by the hydrogen bonds of the $\mathrm{H}_{2} \mathrm{O}$ Van der Waals volume, gives the best predictions to the observations. ${ }^{187}$

The distributions of void volumes in the dry and hydrated PSU systems, calculated with the same probe radius (1.6 $\mathrm{A}$ ) and distance linking the probe centers $(0.5 \AA)$ as already used for the dry systems are displayed in Figure 8. The PAV can be calculated with or without taking into account the

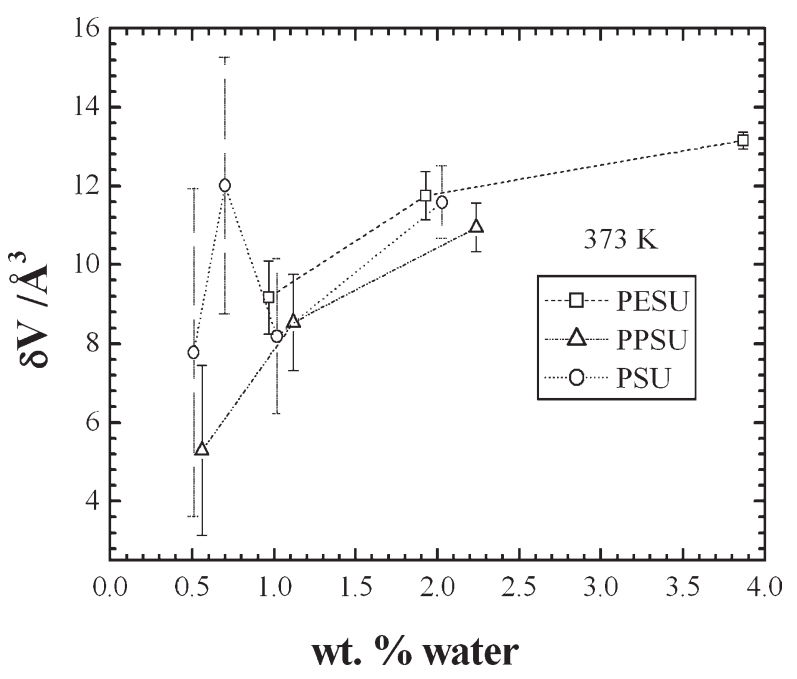

FIGURE 7 Partial molecular volumes ( $\delta V$ ) of water molecules as a function of the water content in the hydrated PESU, PPSU, and PSU models at $373 \mathrm{~K}$. 


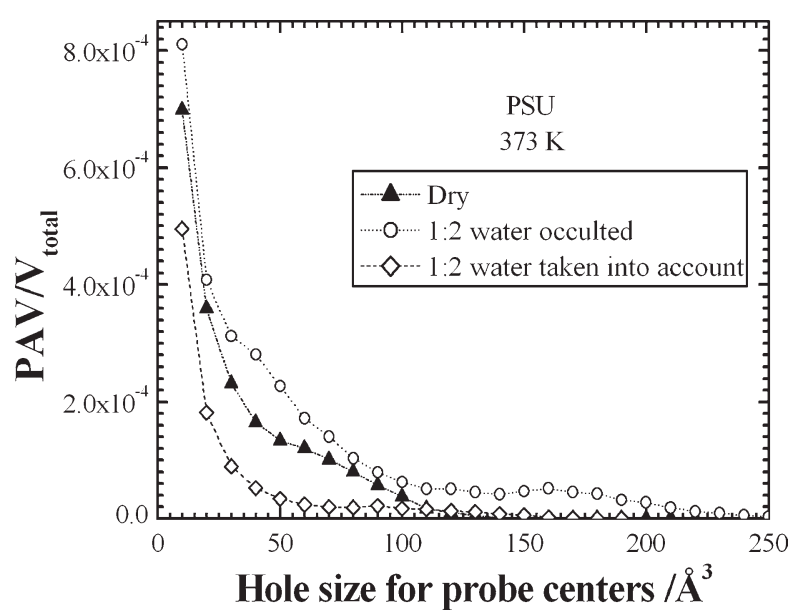

FIGURE 8 Distribution of the amount of probe accessible volume as a function of the hole size in the dry and the hydrated PSU 1:2 models at $373 \mathrm{~K}$. Calculations have been made with and without taking into account the space occupied by water molecules. Data are averaged over all configurations.

penetrants. The first option gives an idea of which type of holes $\mathrm{H}_{2} \mathrm{O}$ occupies, whereas the second one characterizes the influence of the water molecules on the polymer matrix. By comparing the distribution of the PAV in the dry polymer to the hydrated system called PSU 1:2 with option 2, i.e. without taking into account space occupied by $\mathrm{H}_{2} \mathrm{O}$ ("1:2 water occulted" in Fig. 8), we can see that the $\mathrm{H}_{2} \mathrm{O}$ increases the amount of probe accessible volume for the existing hole sizes $\left(<120 \AA^{3}\right)$ and creates larger holes in the polymer matrix $\left(>120 \AA^{3}\right)$. However, no cavitation is created by the presence of $\mathrm{H}_{2} \mathrm{O}$, even for water contents two times superior than experimental saturation. The comparison of the PAV distributions in PSU 1:2 with options 1 ("1:2 water taken into account" in Fig. 8) and 2 ("water occulted") also show that water molecules occupy holes superior to $\sim 20 \AA^{3}$. Although not shown, the same trends are also seen for PESU and PPSU.

The average polymer-water $U_{\text {pol-wat' }}^{\text {total }}$ water-water $U_{\text {wat-wat' }}^{\text {total }}$ total potential, polymer-polymer intermolecular, $U_{\text {pol-pol }}^{\text {inter }}$, and intramolecular $U_{\text {pol-pol }}^{\text {intra }}$ energies were extracted and are reported in Table 2. An appropriate choice of normalization for the energies is slightly complicated in these three polysulfones. We have chosen to give energies in $\mathrm{kJ} \mathrm{mol}^{-1}$ of monomer which in effect corresponds to a normalization by the number of $\mathrm{SO}_{2}$ groups. This has some advantages in terms of comparisons of the electrostatic energies but is less meaningful for the Van der Waals term as the PESU monomer is about half the size of those in PPSU and PSU. For the hydrated systems, a normalization based on the number of water molecules is more appropriate. These factors have to be kept in mind in the following comparisons. The intermolecular ("inter") terms were further resolved into their Van der Waals ("LJ") and Coulombic ("Coul") contributions. The consequences of the volume swelling are visible as a decrease (in absolute value) of the polymer-polymer inter- molecular interactions. The intramolecular term $U_{\text {pol }}^{\text {intra }}$ decreases slightly with the water content. Changes in temperature have greater effects on it. The variations of the $U_{\text {pol-pol }}^{\text {inter } L J}$. and the $U_{\text {pol-pol }}^{\text {inter }}$ are similar. On the contrary, the polymer-water and water-water interactions increase (in absolute value) when the ratio $n_{\mathrm{H}_{2} \mathrm{O}}: n_{\mathrm{SO}_{2}}$, i.e., the water content, increases. This was expected as all the added $\mathrm{H}_{2} \mathrm{O}$ can interact with the polymer and the other $\mathrm{H}_{2} \mathrm{O}$ molecules, and so bring an additional contribution. This contribution is mainly due to the Coulombic terms. It can be observed that the Van der Waals contributions of the water-water interactions are always repulsive. Qualitatively the variations with water content of the polymer-polymer, polymer-water and water-water energies are comparable from one polysulfone to another. In addition, the polymer-water and water-water interaction energies are quantitatively very similar in these three polysulfones, when expressed in terms of the number of $\mathrm{SO}_{2}$ groups. The slight differences that exist can be used to propose a tentative classification of these polymers as a function of the importance of the polymer-water $U_{\text {pol-wat }}^{\text {total }}$ and water-water $U_{\text {wat-wat }}^{\text {total }}$ interactions: PESU $>$ PSU $>$ PPSU for $U_{\text {pol-wat }}^{\text {total }}$ and PESU $>$ PPSU $>$ PSU for $U_{\text {wat-wat }}^{\text {total }}$ Comparisons of the total intermolecular potential energy ( $U_{\text {pot }}^{\text {inter }}$ on Table 2) with that expected on the basis of simple additivity show that the decrease in $U_{\text {pot }}^{\text {inter }}$ is more rapid than the ideal case. It is consistent with the results for the volume variations which, as shown above, are far from additive. This is also consistent with the negative values of the mixing enthalpies reported in Table 4 and calculated according to eq 10:

$$
\begin{aligned}
& \Delta H_{\text {mixing }}= \\
& \frac{\left(n_{\text {monomers }} H_{\text {hydrated polymer }}-n_{\text {monomers }} H_{\text {dry polymer }}-n_{\mathrm{H}_{2} \mathrm{O}} H_{\text {water }}\right)}{n_{\mathrm{H}_{2} \mathrm{O}}}
\end{aligned}
$$

where $\Delta H_{\text {mixing }}$ is the mixing enthalpy (in $\mathrm{kJ} \mathrm{mol}^{-1}$ of $\mathrm{H}_{2} \mathrm{O}$ ), $n_{\text {monomers }}$ is the number of polymer monomers in the simulation box, $n_{\mathrm{H}_{2} \mathrm{O}}$ is the number of $\mathrm{H}_{2} \mathrm{O}$ molecules in the hydrated system, $H_{\text {hydrated polymer }}$ is the enthalpy of the hydrated system (in $\mathrm{kJ} \mathrm{mol}^{-1}$ of monomer), $H_{\text {dry }}$ polymer is the enthalpy of the dry polymer (in $\mathrm{kJ} \mathrm{mol}^{-1}$ of monomer) and $H_{\text {water }}$ is the enthalpy of the SPC/E liquid water at 373 $\mathrm{K}$ (approximately $-42.3 \mathrm{~kJ} \mathrm{~mol}^{-1}$ of $\mathrm{H}_{2} \mathrm{O}$ ). The values given in Table 4 suggest that water sorption is enthalpically more favorable in the PESU than in the two other polysulfones. From the average experimentally determined $\Delta H_{\mathrm{s}}$ values given above $\left(\Delta H_{\mathrm{S}}^{\mathrm{PESU}}=-43 \pm 2 \mathrm{~kJ} \mathrm{~mol}^{-1}, \Delta H_{\mathrm{S}}^{\mathrm{PPSU}}=-42 \pm\right.$ $4 \mathrm{~kJ} \mathrm{~mol}^{-1}$ and $\Delta H_{S}^{P S U}=-37 \pm 2 \mathrm{~kJ} \mathrm{~mol}^{-1}$ ), we can estimate $\Delta H_{\text {mixing }}^{\text {experimental }}$ at $373 \mathrm{~K}$ using $\Delta H_{\text {mixing }}=\Delta H_{\mathrm{s}}+\Delta H_{\mathrm{v}}$ and the enthalpy of vaporization of water, $\Delta H_{\mathrm{v}}(373 \mathrm{~K})=40.657$ $\mathrm{kJ} \mathrm{mol}{ }^{-1}{ }^{234}$ Of course, the $\Delta H_{\text {mixing }}^{\text {expental }}$ determined here can only be a rough approximation to the values at $373 \mathrm{~K}$ as the experiments have been carried out at lower temperatures. However, the values obtained:- $\Delta H_{\text {mixing }}^{\text {PES experimental } \sim-2 \mathrm{~kJ}}$ mol $^{-1}, \Delta H_{\text {mixing }}^{\text {PPSU experimental }} \sim-1 \mathrm{~kJ} \mathrm{~mol}^{-1}$ and $\Delta H_{\text {mixing }}^{\text {PSU experimental }}$ $\sim 4 \mathrm{~kJ} \mathrm{~mol}^{-1}$, are somewhat less negative than is obtained by the models; although water sorption in PESU is again 
TABLE 4 Mixing Enthalpies Calculated from Equation 10 in the PESU, PPSU, and PSU Systems with Different $n_{\mathrm{H}_{2} \mathrm{O}}: n_{\mathrm{SO}_{2}}$ Ratios at $373 \mathrm{~K}$

\begin{tabular}{|c|c|c|c|}
\hline $\begin{array}{l}\text { Ratio } \\
n_{\mathrm{H}_{2} \mathrm{O}}: n_{\mathrm{SO}_{2}}\end{array}$ & $\begin{array}{l}\Delta \mathrm{H}_{\text {mixing }}^{\mathrm{PESU}} \\
\left(\mathrm{kJ} \mathrm{mol}^{-1}\right. \\
\left.\text { of } \mathrm{H}_{2} \mathrm{O}\right)\end{array}$ & $\begin{array}{l}\Delta \mathrm{H}_{\text {mixing }}^{\mathrm{PPSU}} \\
\left(\mathrm{kJ} \mathrm{mol}^{-1}\right. \\
\left.\text { of } \mathrm{H}_{2} \mathrm{O}\right)\end{array}$ & $\begin{array}{l}\Delta \mathrm{H}_{\text {mixing }}^{\mathrm{PSU}} \\
\left(\mathrm{kJ} \mathrm{mol}^{-1}\right. \\
\left.\text { of } \mathrm{H}_{2} \mathrm{O}\right)\end{array}$ \\
\hline 1:8 & $-10 \pm 1$ & $-6 \pm 3$ & $-8 \pm 3$ \\
\hline$\sim 1: 6$ & & & $-7 \pm 3$ \\
\hline $1: 4$ & $-8.9 \pm 0.5$ & $-7 \pm 2$ & $-6 \pm 2$ \\
\hline $1: 2$ & $-8.6 \pm 0.3$ & $-6.3 \pm 0.7$ & $-5 \pm 1$ \\
\hline
\end{tabular}

enthalpically more favorable than in PPSU and PSU. This result could perhaps be indicative of an overestimation of the water-polymer interaction in the models but the differences are probably too small to make any definite conclusions about this.

Figure 9 again reports the polymer-water and water-water total potential energies but this time expressed in $\mathrm{kJ} \mathrm{mol}^{-1}$ of $\mathrm{H}_{2} \mathrm{O}$, so as to try to better assess the behavior with increasing water content. The polymer-water potential energies reflect the finding above concerning the enthalpy that water clearly has a stronger affinity to PESU than to PSU or PPSU. It is also clear that the water-polymer energy is not independent of the water content. There is a general tendency for this contribution to diminish, in absolute terms, whilst a compensatory increase, in absolute terms, occurs in the water-water term.

\section{Specific Interactions}

Favorable interactions between different types of atoms have been identified by examining the corresponding intermolecular radial distribution functions, $g_{\text {inter }}(r)$, and certain are shown in Figure 10. As expected, water hydrogens, $\mathrm{H}_{\text {wat, }}$ have strong specific interactions with the sulfonic oxygens,

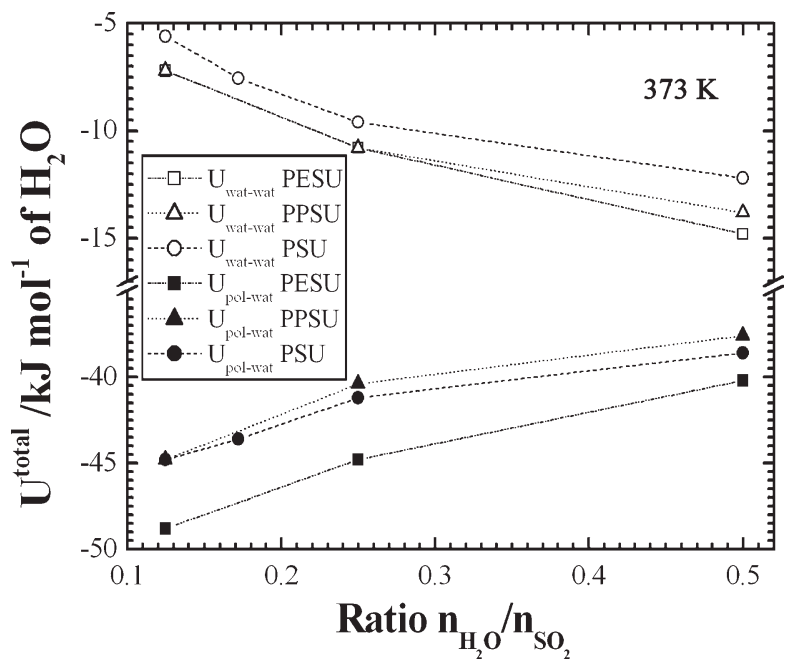

FIGURE 9 Polymer-water $U_{\text {pol-wat }}^{\text {total }}$ and water-water $U_{\text {wat-wat }}^{\text {total }}$ total potential energies in $\mathrm{kJ} \mathrm{mol}^{-1}$ of $\mathrm{H}_{2} \mathrm{O}$ in the PESU, PPSU, and PSU systems at $373 \mathrm{~K}$, as a function of their ratio $n_{\mathrm{H}_{2} \mathrm{O}}: n_{\mathrm{SO}_{2}}$.

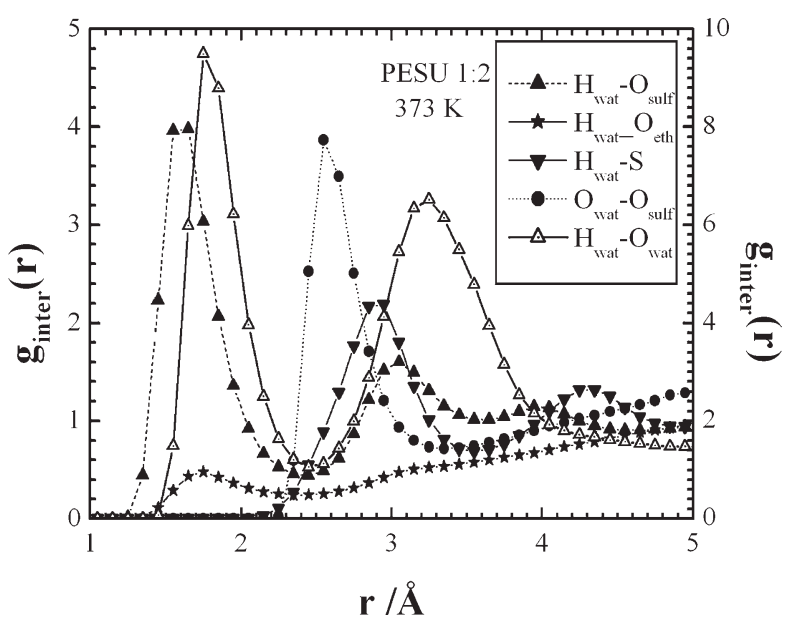

FIGURE 10 Intermolecular radial distribution functions $g_{\text {inter }}(r)$ between the water molecules (water oxygen $\mathrm{O}_{\text {wat }}$ or water hydrogen $\mathrm{H}_{\text {wat }}$ ) and different sites of the polymer or of the neighbouring $\mathrm{H}_{2} \mathrm{O}$ in the PESU $1: 2$ system at $373 \mathrm{~K}$. The scale on the right axis is only for the $\mathrm{H}_{\text {wat }}-\mathrm{O}_{\text {wat }}$ rdf.

$\mathrm{O}_{\text {sulf, }}$ and the oxygens of neighboring $\mathrm{H}_{2} \mathrm{O}$, and, to a lesser extent, with the ether oxygens, $\mathrm{O}_{\text {eth. }}$. On $g_{\text {inter }}(r)$ distributions, this is characterized by a peak between $\sim 1.4$ and $\sim 2.4 \AA$, which corresponds to the lower and the upper hydrogen bond distances between a hydrogen and an oxygen. ${ }^{238,239}$ Indirect peaks resulting from these interactions on distributions such as water oxygen $\mathrm{O}_{\text {wat }}$ and $\mathrm{O}_{\text {sulf, or sulfur } \mathrm{S} \text { and }}$ $\mathrm{H}_{\text {wat }}$ are also present but at larger distances as can be seen in Figure 10 for the PESU 1:2 system. Thus, as seen in other atomistic simulations, ${ }^{115,116,118-120,124,127,130,132,133,136,138,146-}$ $148,151,156,180$ the study of $g_{\text {inter }}(r)$ suggests the existence of hydrogen bonds between the water molecules and the hydrophilic sites. Hydrophilic sites identified in the polysulfones under study are $\mathrm{O}_{\text {sulf }}, \mathrm{O}_{\text {eth }}$, and $\mathrm{O}_{\text {wat }}$.

As for PMDA-ODA, ${ }^{156}$ hydrogen bonds have been characterized using a simple geometrical criteria. Based on the first minimum in the $g_{\text {inter }}(r)$ for $\mathrm{H}_{\text {wat }}-\mathrm{O}_{\text {wat }}$ and $\mathrm{H}_{\text {wat }}-\mathrm{O}_{\text {sulf, }}$ and also on the experimentally-quoted limits of the hydrogen bonds, ${ }^{239}$ a hydrogen bond is defined each time a $\mathrm{H}_{\text {wat }}$ is less than $2.4 \AA$ from a hydrophilic site $\left(d_{\mathrm{H} \cdots \mathrm{O}} \leq 2.4 \AA\right)$. Our experience with PMDA-ODA is that the $0 \cdots \mathrm{H}_{\text {wat }}-\mathrm{O}_{\text {wat }}$ angle is not a discriminating parameter, which is also confirmed for these polysulfones; probability density distributions of the cosine of the $0 \cdots \mathrm{H}_{\text {wat }}-\mathrm{O}_{\text {wat }}$ angle (not shown) show a single Gaussian peak centered at $180^{\circ}$.

The static and dynamic analysis of the hydrogen bonds ( $\mathrm{H}$ bonds) gives much information. To present this in a clear way, this study will be divided into two parts: "From the acceptor point of view" which is centered on the behavior of the acceptor sites of H-bonds, and "From the donor point of view" which concerns the way the $\mathrm{H}_{2} \mathrm{O}$ molecules are hydrogen bonded.

\section{From the H-Bond Acceptor Point of View}

Figure 11 shows the ratio $n_{\mathrm{O}_{x} \mathrm{H} \text {-bonded }} n_{\mathrm{H}_{2} \mathrm{O}}$ between the number of $\mathrm{H}$-bonded acceptors $\left(\mathrm{O}_{\text {sulf }}, \mathrm{O}_{\text {eth }}\right.$, and $\left.\mathrm{O}_{\text {wat }}\right)$ and the 


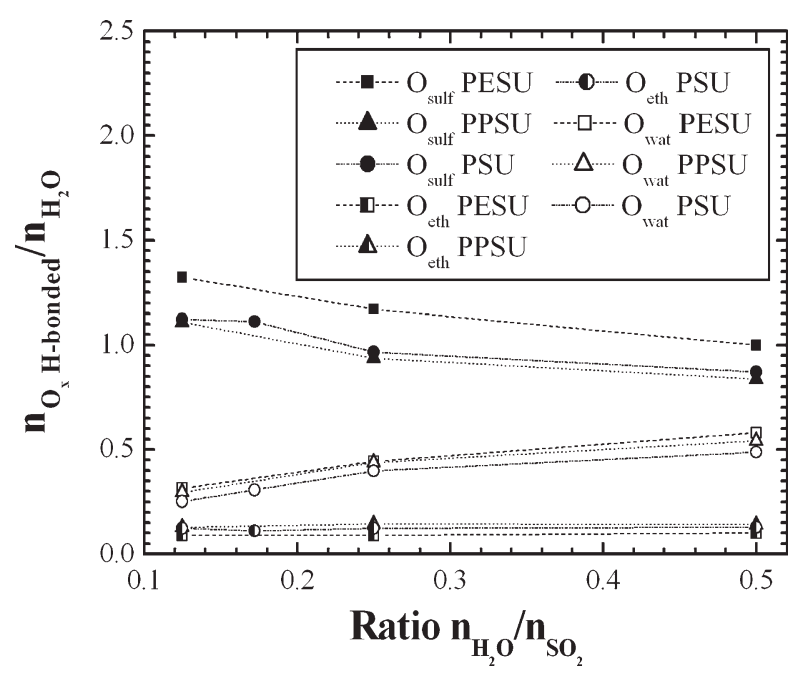

FIGURE 11 The ratio $n_{\mathrm{O}_{x} \mathrm{H} \text {-bonded }}: n_{\mathrm{H}_{2} \mathrm{O}}$ between the number of $\mathrm{H}$-bonded acceptors $\left(\mathrm{O}_{\text {sulf, }}, \mathrm{O}_{\text {eth }}\right.$, and $\left.\mathrm{O}_{\text {wat }}\right)$ and the number of water molecules plotted as a function of the ratio $n_{\mathrm{H}_{2} \mathrm{O}}: n_{\mathrm{SO}_{2}}$ in the PESU, PPSU, and PSU hydrated systems at $373 \mathrm{~K}$.

number of $\mathrm{H}_{2} \mathrm{O}$ in the hydrated models of PESU, PPSU and PSU as a function of the water content, expressed as the ratio $n_{\mathrm{H}_{2} \mathrm{O}}: n_{\mathrm{SO}_{2}}$. It is clear that significantly more $\mathrm{O}_{\text {sulf }}$ are hydrogen bonded with $\mathrm{H}_{2} \mathrm{O}$ molecules than the other hydrophilic site in the polysulfones, $\mathrm{O}_{\text {eth }}$. This confirms experimental studies which consider the $\mathrm{O}_{\text {sulf }}$ as the main reason for the hydrophilicity of these polymers. ${ }^{64,108}$ The values of $n_{\mathrm{O}_{x} \mathrm{H} \text {-bonded }}: n_{\mathrm{H}_{2} \mathrm{O}}$ superior to 1 arise due to water molecules forming two hydrogen bonds with two different acceptor sites. This phenomenon of "water bridging" will be discussed in the next section. It is also interesting to note from Figure 11 that although the proportion of $\mathrm{O}_{\text {eth }}$ sites $\mathrm{H}$-bonded to water remains constant with increasing water content, that of the $\mathrm{O}_{\text {sulf }}$ decreases. The behavior of the $\mathrm{H}$-bonding to $\mathrm{O}_{\text {eth }}$ sites suggests that it is driven simply by the water concentration; results proportional to water concentration are also obtained for the number of close encounters between atoms on the polymer chain and water molecules where no $\mathrm{H}$ bonding is possible. The decrease in the proportion of $\mathrm{O}_{\text {sulf }}$ sites $\mathrm{H}$-bonded to water is, however, concomitant with an increase in the proportion of water molecules H-bonded to others, i.e., clustering; at the lowest water content about a $1 / 4$ of water molecules are $\mathrm{H}$-bonded to others whereas at the higher contents this increases to about $1 / 2$. This behavior reflects the findings, described above, for the behavior of the polymer-water and water-water interaction energies with water content and suggests that it is the interactions with the $\mathrm{O}_{\text {sulf }}$ groups which are responsible for the nonlinearity.

Some care should be taken interpreting Figure 11 because for water contents near experimental saturation, i.e., $n_{\mathrm{H}_{2} \mathrm{O}}: n_{\mathrm{SO}_{2}} \approx 1: 4$ for PESU and PPSU, and $n_{\mathrm{H}_{2} \mathrm{O}}: n_{\mathrm{SO}_{2}} \approx 1: 6$ for PSU, the ratio $n_{\mathrm{O}_{x} \mathrm{H} \text {-bonded }}: n_{\mathrm{H}_{2} \mathrm{O}}$ is about $1.2,0.9$ and 1.1 for PESU, PPSU, and PSU, respectively, which does not mean that almost all $\mathrm{O}_{\text {sulf }}$ are hydrogen bonded to one $\mathrm{H}_{2} \mathrm{O}$. In fact, for these water contents, only $\sim 15 \%$ of the $0_{\text {sulf }}$ in PESU, $\sim 12 \%$ in PPSU and $\sim 10 \%$ in PSU are hydrogen bonded with a $\mathrm{H}_{2} \mathrm{O}$. In other words, at experimental saturation, more than $85 \%$ of the more hydrophilic sites of the polysulfones are still available. It has been suggested that this behavior could be simply due to the fact that some sites are inaccessible. ${ }^{115} \mathrm{We}$ will return later to the accessibility of the hydrophilic sites.

As we have seen, at water contents near the experimental water saturation, $\sim 15 \%$ of the $0_{\text {sulf }}$ in the PESU, $\sim 12 \%$ in the PPSU and $\sim 10 \%$ of the $\mathrm{O}_{\text {sulf }}$ in the PSU models are hydrogen bonded with $\mathrm{H}_{2} \mathrm{O}$ molecules at any particular instant in time. However, Table 5, which reports the percentages of different acceptors hydrogen bonded at least one time with $\mathrm{a}_{2} \mathrm{O}$ during the simulations, shows that these values are well below the percentages of the acceptor sites visited during the simulations. We can also add that, the values reported in the Table 5 are not the maximum values of sites potentially accessible since we do not observe a plateau in the timescale of the simulation. In other words, it is certain that $59.4 \%$ of the $\mathrm{O}_{\text {sulf }}$ are visited during the simulation of the PESU 1:4 system, and thus a minimum of $59.4 \%$ of $\mathrm{O}_{\text {sulf }}$ are accessible. However, without doing much longer simulations we do not have access to the total percentage of $\mathrm{O}_{\text {sulf }}$ accessible in this system. Of course, it could be argued that local fluctuations lead to only a subset of these sites being accessible at any one instant in time; demonstrating that this is or isn't the case might be feasible using simulation, e.g. by a judicious choice of initial configurations for the water molecules, but this has not been attempted as yet. We are certain though that interpreting the low ratio of water to polymer hydrophilic sites at experimental saturation by the permanent inaccessibility of a large fraction of the sites is incorrect.

Many water oxygens form at least one hydrogen bond during the simulation with another water molecule. The accessibility of these sites is largely related to $\mathrm{H}_{2} \mathrm{O}$ mobility and this will be discussed later.

The dynamics of the H-bonds have also been analyzed. In our previous article on PMDA-ODA, ${ }^{156}$ we had studied the

TABLE 5 Percentages of $\mathrm{O}_{\text {sulf }}, \mathrm{O}_{\text {eth }}$, and $\mathrm{O}_{\text {wat }}$ Which Form at Least One Hydrogen Bond with a Water Molecule Over a Period of 4000 ps at $373 \mathrm{~K}$

\begin{tabular}{llll}
\hline System & $\% \mathrm{O}_{\text {sulf }}$ & $\% \mathrm{O}_{\text {eth }}$ & $\% \mathrm{O}_{\text {wat }}$ \\
PESU 1:8 & 40.5 & 25.5 & 85.6 \\
PESU 1:4 & 59.4 & 40.3 & 94.0 \\
PESU 1:2 & 73.6 & 55.4 & 98.1 \\
PPSU 1:8 & 35.2 & 20.1 & 80.8 \\
PPSU 1:4 & 45.1 & 27.1 & 93.2 \\
PPSU 1:2 & 60.7 & 39.9 & 95.8 \\
PSU 1:8 & 39.3 & 20.4 & 75.2 \\
PSU sat & 43.1 & 21.8 & 81.4 \\
PSU 1:4 & 48.4 & 27.1 & 92.0 \\
PSU 1:2 & 66.5 & 42.8 & 94.8
\end{tabular}


continuous lifetime and looked at a correlation function analysis to take into account the global lifetime of the same $\mathrm{H}$ bond in case it was alternately broken and reformed. In fact, the continuous lifetime analysis considers that such an $\mathrm{H}$ bond is a different one after each break. Thus, it seems that it is more judicious to characterize the H-bond lifetimes by using a correlation function analysis, as has already been used in the past. ${ }^{240,241}$ Details of this analysis have already been given ${ }^{156}$ so only the main steps will be explained here.

A function is defined for each pair ij of possible $\mathrm{H}$-bond donors and acceptors, which just takes the values 1 and 0 according to whether an $\mathrm{H}$-bond exists between them. In our case, this is simply based on their distance apart at time $t$, $r_{i j}(t)$, in the following way:

$$
\begin{aligned}
& H\left\{r_{i j}(t)\right\}=1 \text { if } r_{i j}(t) \leq d_{H \ldots O} \\
& H\left\{r_{i j}(t)\right\}=0 \text { if } r_{i j}(t)>d_{H \ldots O}
\end{aligned}
$$

The autocorrelation function $R(t)=\left\langle H\left\{r_{i j}(0)\right\} H\left\{r_{i j}(t)\right\}\right\rangle$ then gives a description of the decay of the H-bond. In practice, we obtain this characteristic time for each type of H-bond from the normalized form of $R(t)$, which we refer to as $C(t) .{ }^{130}$ The normalization is straightforward for these types of functions that only take values of 1 and 0 as $R(0)=\left\langle H\left\{r_{i j}(0)\right\} H\left\{r_{i j}(0)\right\}\right\rangle=\left\langle H\left\{r_{i j}(0)\right\}\right\rangle$ :

$$
\begin{aligned}
C(t)= & \frac{R(t)-\left\langle H\left\{r_{i j}(0)\right\}\right\rangle^{2}}{\left\langle H^{2}\left\{r_{i j}(0)\right\}\right\rangle-\left\langle H\left\{r_{i j}(0)\right\}\right\rangle^{2}} \\
& =\frac{R(t)-\left\langle H\left\{r_{i j}(0)\right\}\right\rangle^{2}}{\left\langle H\left\{r_{i j}(0)\right\}\right\rangle-\left\langle H\left\{r_{i j}(0)\right\}\right\rangle^{2}}=\frac{R(t)-R^{2}(0)}{R(0)-R^{2}(0)}
\end{aligned}
$$

The normalized $C(t)$ thus gives the probability of an H-bond still existing between two atoms at some later time, given that it did exist at the time origin. As it could have been broken and reformed several times in the intervening time, it does not give the same information as the continuous lifetime analysis.

The resulting $C(t)$ all showed a similar behavior than that found for PMDA-ODA, ${ }^{156}$ i.e., a highly nonexponential relaxation at short times and a slow exponential decay at long times. The combination of both these quite different behaviors had been found to be well fitted by using a weighted sum of a single exponential and a stretched exponential. ${ }^{156}$ so the same expression was also used here:

$$
C(t)=\lambda \exp \left(-\frac{t}{\gamma}\right)+(1-\lambda) \exp \left(-\left(\frac{t}{\alpha}\right)^{\beta}\right)
$$

The corresponding relaxation times, $\tau$, could then be obtained from the best-fit values of the $\lambda, \gamma, \alpha$, and $\beta$ parameters and the analytical integration of eq 14 :

$$
\begin{aligned}
\tau=\int_{0}^{\infty} C(t) d t=\int_{0}^{\infty} \lambda \exp \left(-\frac{t}{\gamma}\right) & +(1-\lambda) \exp \left(-\left(\frac{t}{\alpha}\right)^{\beta}\right) d t \\
& =\lambda \gamma+(1-\lambda) \frac{\alpha}{\beta} \Gamma\left(\frac{1}{\beta}\right)
\end{aligned}
$$

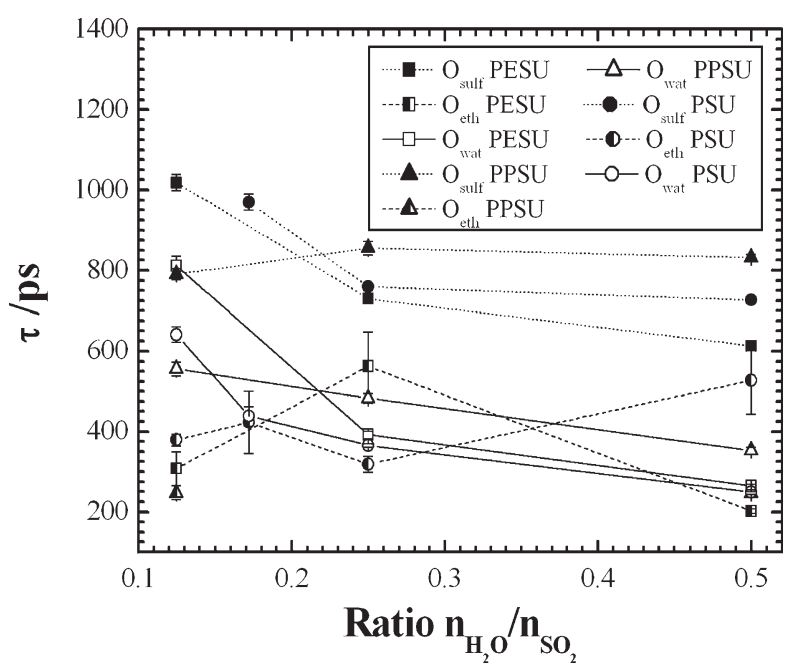

FIGURE $12 \mathrm{H}$-bond correlation times, as evaluated from eq 15, plotted for the hydrophilic sites $\mathrm{O}_{\text {sulf }}, \mathrm{O}_{\text {eth, }}$ and $\mathrm{O}_{\text {wat }}$ in the PESU, PPSU, and PSU systems as a function of the $n_{\mathrm{H}_{2} \mathrm{O}}: n_{\mathrm{SO}_{2}}$ ratio.

where the gamma function, $\Gamma(x)$, was estimated to high precision using a standard numerical technique. ${ }^{242}$

The values of $\tau$ obtained for H-bonds with the three types of acceptor sites on the polysulfone systems are displayed in Figure 12 as a function of the ratio $n_{\mathrm{H}_{2} \mathrm{O}}: n_{\mathrm{SO}_{2}}$, i.e., the water content. In PMDA-ODA, the main hydrophilic sites were the carbonyl oxygens $\mathrm{O}_{\text {carb }}{ }^{156}$ In polysulfones, a similar structure is encountered with main hydrophilic site $\mathrm{O}_{\text {sulf }}$ and with less interactive $\mathrm{O}_{\text {eth. }}$. The trend, $\tau_{\mathrm{O}_{\text {carb }}}>\tau_{\mathrm{O}_{\text {wat }}} \sim \tau_{\mathrm{O}_{\text {eth }}}$, observed in PMDA-ODA is similar to that found here with $\tau_{\mathrm{O}_{\text {sulf }}}>\tau_{\mathrm{O}_{\text {wat }}} \sim \tau_{\mathrm{O}_{\text {eth }}}$. Here also $\tau_{\mathrm{O}_{\text {eth }}}$ is almost constant whereas $\tau_{\mathrm{O}_{\text {sulf }}}$ and $\tau_{\mathrm{O}_{\text {wat }}}$ decrease when the water content increases, which is in agreement with findings from MD simulations of PVA hydrogels and PEO solutions. ${ }^{130,133}$ No general trend of $\tau$ with the type of the polysulfone can be distinguished. However, it is clear that, for all types, the correlation lifetimes of the H-bonds are about twice as long in these polysulfones than in PMDA-ODA. ${ }^{156}$ We can note here that the averages of experimentally determined diffusion coefficients of water in PMDA-ODA, PESU and PSU between 23 and $50{ }^{\circ} \mathrm{C}$ are $\sim 0.27$ $\times 10^{-8} \mathrm{~cm}^{2} \mathrm{~s}^{-1,75,105,243-248} \sim 8 \times 10^{-8} \mathrm{~cm}^{2} \mathrm{~s}^{-1,64,199,200,249}$ and $\sim 9 \times 10^{-8} \mathrm{~cm}^{2} \mathrm{~s}^{-1}$, respectively. ${ }^{9,16,29,64,199,213}$ This would suggest that the $\mathrm{H}$-bond lifetime is not the critical parameter for defining water diffusion if the models reproduced the same tendencies for the diffusion coefficients. Unfortunately, as will be discussed later, a simulation time scale of 5 ns is insufficient to obtain diffusion coefficients of water in these dense polymer models. However, the observations do agree with Kucukpinar et al., who found that water diffusion was not really affected by the values of the water-polymer interactions in a model of hydrated NBR, and so deduced that these interactions do not govern the water diffusion. ${ }^{150}$

\section{From the H-Bond Donor Point of View}

The average number of $\mathrm{O}_{\text {sulf }}, \mathrm{O}_{\text {eth }}$, and $\mathrm{O}_{\text {wat }}$ visited by one $\mathrm{H}_{2} \mathrm{O}$ during a period of 4000 ps have been calculated from 


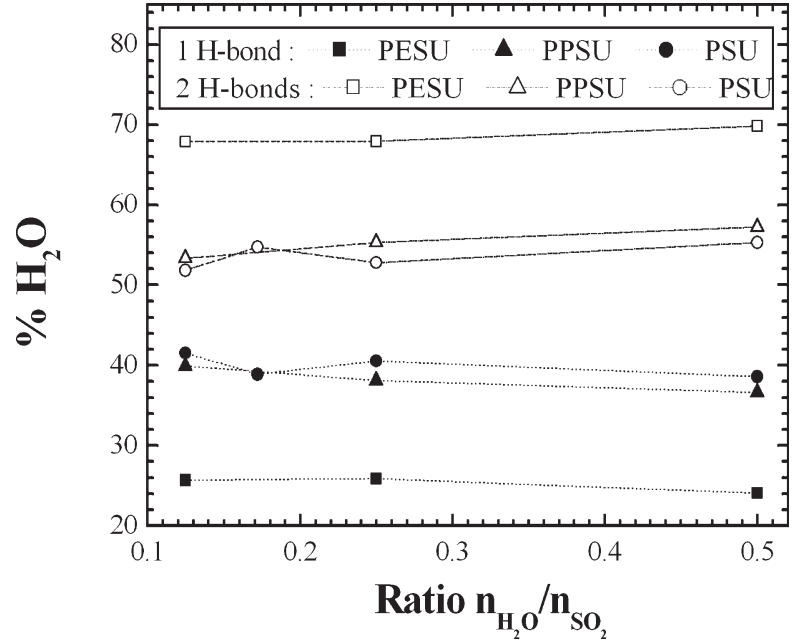

FIGURE 13 Percentages of $\mathrm{H}_{2} \mathrm{O}$ molecules which form one (1 $\mathrm{H}$-bond) or two (2 $\mathrm{H}$-bonds) hydrogen bonds through their hydrogens in the PESU, PPSU, and PSU systems with different $n_{\mathrm{H}_{2} \mathrm{O}}: n_{\mathrm{SO}_{2}}$ ratios at $373 \mathrm{~K}$. Water molecules not forming any $\mathrm{H}-$ bonds and those forming more than $2 \mathrm{H}$-bonds are not reported on this graph but represent $\sim 6 \%$ of the total.

the production runs. From these averages, it is clear that at the same $n_{\mathrm{H}_{2} \mathrm{O}}: n_{\mathrm{SO}_{2}}$ ratio the $\mathrm{H}_{2} \mathrm{O}$ molecules visit more polymer sites in the PESU than in the PPSU and the PSU. This is particular the case as far as the $0_{\text {sulf }}$ are concerned, e.g., 17.1 $\pm 0.5,12.1 \pm 0.1$, and $12.7 \pm 0.2$, for PESU, PPSU, and PSU respectively for a $n_{\mathrm{H}_{2} \mathrm{O}}: n_{\mathrm{SO}_{2}}$ ratio of $1: 8$. This is consistent with Table 5 where we have seen that more acceptor sites on the polymer are visited in the PESU. However, it has to be remembered that there are twice as many sulfonic groups in the PESU system so their concentration is higher than PSU and PPSU. This would then suggest that water in fact is less mobile in PESU as the difference in the number of $\mathrm{O}_{\text {sulf }}$ groups visited for a given $n_{\mathrm{H}_{2} \mathrm{O}}: n_{\mathrm{SO}_{2}}$ compared to PSU and PPSU is less than a factor of two. As will be seen later, this is what is found when the trajectories are analyzed.

Although it appears that for water contents up to the experimental saturation the number of $\mathrm{O}_{\text {wat }}$ visited in 4000 ps is small, $\sim 5$ to 8 , and comparable to that of the $0_{\text {eth }}$, it again has to be taken into account that the water concentrations are lower compared to the other acceptor sites. The fact that the number of sites visited is roughly comparable results from the mobility of the $\mathrm{H}_{2} \mathrm{O}$ molecules.

Figure 13 reports the percentages of water molecules forming 1 or $2 \mathrm{H}$-bonds through their hydrogens at the same time. Although there are "free" water molecules, i.e., not at all H-bonded, and even some H-bonded to more than 2 sites, the sum of these rarer kinds does not exceed $6 \%$. We can see in Figure 13 that a majority of water molecules form two H-bonds and that there is only a small dependence of the percentages on the water content. This low dependence is in contrast to the behavior of the water-polymer and water-water interaction energies and suggests that subtle changes occur in the H-bonding pattern and this is discussed in the next section concerning the water bridging. The actual percentages of water molecules with $2 \mathrm{H}$-bonds are very similar in PSU and PPSU, but are $~ 15 \%$ higher in PESU. This may be explained to a large extent by the higher concentrations of sulfonic groups in the PESU system compared to PSU and PPSU at the same ratio of $n_{\mathrm{H}_{2} \mathrm{O}}: n_{\mathrm{SO}_{2}}$. Although this implies a higher concentration of water too in PESU, Figure 11 suggests this is not a big factor.

\section{Water Bridging}

As can be seen in Figure 13, $70 \%$ in the PESU and $\sim 55 \%$ in the PPSU and the PSU of the $\mathrm{H}_{2} \mathrm{O}$ form two hydrogen bonds at the same time. The hypothesis of the existence of such $\mathrm{H}_{2} \mathrm{O}$ molecules in polymers has already been made by experimentalists, ${ }^{62,64,83,88,98,108}$ and seen in simulations of hydrated polymers. ${ }^{115}$ In particular Gaudichet et al. have made the hypothesis that "water is always doubly bonded to polar groups by hydrogen bonds." ${ }^{64,108}$ However, they only took into account $\mathrm{O}_{\text {sulf }}$ atoms as interaction sites, neglecting the $\mathrm{O}_{\text {eth }}$ and $\mathrm{O}_{\text {wat }}$ which have been shown in the present study to be important as well.

As shown in Table 6, the total number of bridges increases with the water content but the proportion of $\mathrm{H}_{2} \mathrm{O}$ forming a bridge stays approximately constant in each polymer system. The more numerous water bridges at low water content link two polymer sites (P-W-P). Then, if the number of these kind of bridges increases with water content, the bridges linking one polymer site and one $\mathrm{H}_{2} \mathrm{O}(\mathrm{P}-\mathrm{W}-\mathrm{W}$ ) gradually become as frequent. Few bridges are formed between two water molecules (W-W-W) at low water content but their proportion increases to slightly more than $10 \%$ at the highest concentration. This suggests that few water clusters exist at low concentrations but their number and size should increase with water concentration. A more extended study of the water clusters is done in the next section.

This gradual change in the bridging pattern with water concentration, most notably in the percentages of $\mathrm{P}-\mathrm{W}-\mathrm{P}$ and $\mathrm{P}-\mathrm{W}-\mathrm{W}$ bridges, is clearly the mechanism underlying the concomitant changes seen in the water-polymer and waterwater contributions to the potential energy (Fig. 9). It is thus very likely that it also plays a key role in determining water solubility. Qualitatively, if the environment experienced by a water molecule resembles more and more that in pure water then the incentive to dissolve in the polymer must in some way diminish.

The less hydrophilic behavior of the $\mathrm{O}_{\text {eth }}$ is demonstrated by the low number of water bridges which imply $\mathrm{O}_{\text {eth. We also }}$ find some "cyclic bridges," where both hydrogens from the same water molecule form a loop with only one acceptor, but this involves at the most, in all the simulations under study, $1 \%$ of the bridges for the $\mathrm{O}_{\text {sulf }}$ and less than $0.1 \%$ for the $\mathrm{O}_{\text {eth }}$ and $\mathrm{O}_{\text {wat }}$ sites. However, intramolecular bridges represent $\sim 7 \%$ of the bridges in the PESU models, $\sim 5 \%$ in the PPSU models, and $~ 9 \%$ in the PSU models. Minimum distances for $\mathrm{O}_{\text {sulf }}-\mathrm{O}_{\text {sulf }}$ and $\mathrm{O}_{\text {sulf }}-\mathrm{O}_{\text {eth }}$ oxygens of a same monomer are $\sim 2.5 \AA$ and $\sim 6.6 \AA$, respectively, in the PESU, PPSU or 
TABLE 6 Numbers and Percentages of the Different Types of Water Bridges Between Two Hydrophilic Sites

\begin{tabular}{|c|c|c|c|c|c|c|c|c|c|}
\hline Systems & $\mathrm{O}_{\text {sulf }}-\mathrm{W}-\mathrm{O}_{\text {sulf }}$ & $\mathrm{O}_{\text {sulf }}-\mathrm{W}-\mathrm{O}_{\text {eth }}$ & $\mathrm{O}_{\text {eth }}-\mathrm{W}-\mathrm{O}_{\text {eth }}$ & P-W-P & $\mathrm{O}_{\text {sulf }}-\mathrm{W}-\mathrm{O}_{\text {wat }}$ & $\mathrm{O}_{\text {eth }}-\mathrm{W}-\mathrm{O}_{\text {wat }}$ & P-W-W & W-W-W & $\% \mathrm{H}_{2} \mathrm{O}$ \\
\hline PESU 1:8 & $114(59)$ & $15(8)$ & $0(0)$ & $129(67)$ & $52(27)$ & $5(3)$ & $57(30)$ & $6(3)$ & 72 \\
\hline PESU 1:4 & $181(48)$ & $27(7)$ & $1(0)$ & $209(55)$ & $138(36)$ & $13(3)$ & $151(40)$ & $21(6)$ & 71 \\
\hline PESU 1:2 & $281(36)$ & $49(6)$ & $2(0)$ & $331(42)$ & $321(41)$ & $42(5)$ & $363(46)$ & $88(11)$ & 73 \\
\hline PPSU 1:8 & $37(51)$ & $10(14)$ & $0(0)$ & 47 (65) & $20(28)$ & $3(4)$ & $23(32)$ & $2(3)$ & 55 \\
\hline PPSU 1:4 & $55(37)$ & $19(13)$ & $1(1)$ & $75(50)$ & $51(34)$ & $10(7)$ & $62(41)$ & $13(9)$ & 57 \\
\hline PPSU 1:2 & $97(31)$ & $31(10)$ & $2(1)$ & $130(42)$ & $115(37)$ & $26(8)$ & $141(46)$ & $37(12)$ & 59 \\
\hline PSU 1:8 & $40(59)$ & $10(15)$ & $1(1)$ & $50(74)$ & $14(21)$ & $2(3)$ & $16(24)$ & $2(3)$ & 53 \\
\hline PSU sat & $55(56)$ & $12(12)$ & $0(0)$ & $67(68)$ & $24(24)$ & $4(4)$ & $28(28)$ & $4(4)$ & 56 \\
\hline PSU 1:4 & $61(44)$ & $17(12)$ & $1(1)$ & $79(56)$ & $44(31)$ & $8(6)$ & $52(37)$ & $9(6)$ & 54 \\
\hline PSU 1:2 & $106(36)$ & $34(12)$ & $1(0)$ & $141(48)$ & $101(35)$ & $19(7)$ & $120(41)$ & $31(11)$ & 56 \\
\hline
\end{tabular}

$\mathrm{P}$ refers to a polymer site and $\mathrm{W}$ to a water site. The bridges have been analyzed over 5000 ps at $373 \mathrm{~K}$ both as a function of water content and as a function of the $\mathrm{H}$-bond acceptor sites being $\mathrm{O}_{\text {sulf }}, \mathrm{O}_{\text {eth, }}$ or $\mathrm{O}_{\text {wat }}$. Results for each specific bridge type and each water content include the average number of bridges in the simulation cell and its total percentage with respect to the number of bridges in the systems (in parentheses) Columns " $\mathrm{P}-$ $\mathrm{W}-\mathrm{P}$," "P-W-W," and "W-W-W" are the sums of the water bridges formed between two polymer sites, one polymer site and another $\mathrm{H}_{2} \mathrm{O}$, and two $\mathrm{H}_{2} \mathrm{O}$ respectively. The average percentage of water molecules acting as bridges is also displayed in the column "\% $\mathrm{H}_{2} \mathrm{O}$."

PSU models. If we consider $\mathrm{H}$-bond angles of $180^{\circ}$ and lower and upper limit distances $\mathrm{H}_{\text {wat }}-\mathrm{O}_{\text {sulf }}$ or $\mathrm{H}_{\text {wat }}-\mathrm{O}_{\text {eth }}$ of 1.4 and $2.4 \AA$, the boundary distances between two hydrophilic sites so that a $\mathrm{H}_{2} \mathrm{O}$ could form a bridge between them are 3.9 and $5.6 \AA$. Under these strict conditions, we would not have any "water bridges" between two acceptor sites of a same monomer and the intramolecular contribution would thus be due to the close approach of different parts of the same chain. However, to characterize the actual distances between waterbridged acceptor sites, each bridge has been examined and the distance, $d$, separating the two acceptor sites has been calculated. This distance has then been used to calculate the contribution, $g(d)$, to the corresponding radial distribution function for the pairs of hydrophilic sites actually engaged in water bridges. If we look at Figure 14, which reports this radial distribution function for the different types of bridges, we can see that the upper and lower bounds of $d$ in our simulations are in fact $d_{\mathrm{l}}=2.4 \pm 0.1 \AA$ and $d_{\mathrm{u}}=6.0 \pm 0.1 \AA$. This means that, within our purely distance defined definition of an $\mathrm{H}$-bond, intramolecular bridges between two $\mathrm{O}_{\text {sulf }}$ of a same sulfonic group can exist. In fact, they represent $\sim 0.9 \pm 0.2 \%$ of the bridges in the PESU and PSU models, and $\sim 1.9 \pm 0.4 \%$ of the bridges in the PPSU models. They are characterized by a small peak at $\sim 2.5 \AA$ in the $\mathrm{O}_{\text {sulf }}-\mathrm{W}$ $\mathrm{O}_{\text {sulf }}$ distribution shown in Figure 14. We also observe a peak at $\sim 2.7 \AA$ in the $\mathrm{O}_{\text {wat }}-\mathrm{W}-\mathrm{O}_{\text {wat }}$ distribution. This peak results from configurations where the hydrogen atoms of one water molecule form H-bonds with oxygens in two other water molecules which themselves are already H-bonded. These two particular peaks are also visible on the PPSU and PSU hydrated models.

From the total radial distribution functions, $g(r)$, for the two types of atoms involved in bridges, it is also possible to calculate the number density of pairs of hydrophilic sites $\left(n_{\text {pairs }}^{I J}\right)$ which fall within the upper and lower bounds for $d$ previously found:

$$
n_{\text {pairs }}^{I J}=\frac{1}{V\left(1+\delta_{I J}\right)}\left(\frac{4 \pi N_{J} N_{I}}{V} \int_{r=d_{1}}^{r=d_{\mathrm{u}}} r^{2} g(r) d r\right)
$$

Where $N_{I}$ and $N_{J}$ are the numbers of atoms of types I and J, respectively, in the simulation box of volume $V$. The term $\delta_{I J}$ $=1$, if $I=J$, or 0 , if $I \neq J$, takes into account the double counting in the case of like types. In effect, $n_{\text {pairs }}^{I J}$ is an upper limit for the average number of "bridges" that could potentially exist at any one instant. In reality, some pairs can lie within the range of $d$ required but not be able to be bridged by a water molecule due to other atoms occupying the space between them. At this stage, we make no attempt to assess

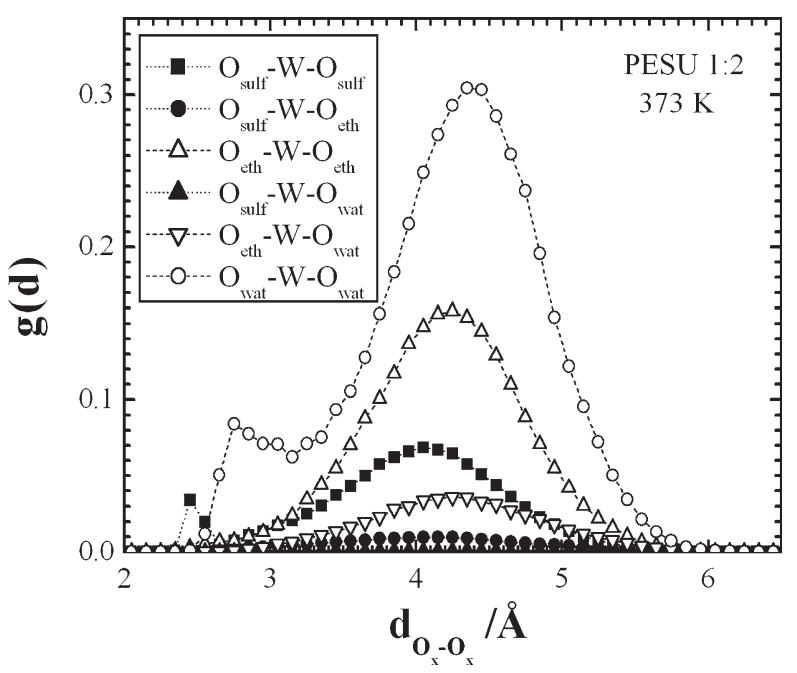

FIGURE 14 The contributions, $g(d)$, to the radial distribution functions of $\mathrm{H}$-bond acceptor sites, which are involved in water bridges. $g(d)$ is reported for the different types of bridges in the PESU 1:2 system analyzed over 5000 ps at $373 \mathrm{~K}$. 
TABLE 7 Characteristics of Hydrophilic Sites

\begin{tabular}{|c|c|c|c|c|c|c|c|}
\hline $\begin{array}{l}\text { System (Number } \\
\text { of } \mathrm{H}_{2} \mathrm{O} \mathrm{nm}^{-3} \text { ) }\end{array}$ & $\begin{array}{l}\text { Number } \\
\text { Density }\end{array}$ & $\mathrm{O}_{\text {sulf }}-\mathrm{W}-\mathrm{O}_{\text {sulf }}$ & $\mathrm{O}_{\text {sulf }}-\mathrm{W}-\mathrm{O}_{\text {eth }}$ & $\mathrm{O}_{\text {eth }}-\mathrm{W}-\mathrm{O}_{\text {eth }}$ & $\mathrm{O}_{\text {sulf }}-\mathrm{W}-\mathrm{O}_{\text {wat }}$ & $\mathrm{O}_{\text {eth }}-\mathrm{W}-\mathrm{O}_{\text {wat }}$ & $\mathrm{O}_{\text {wat }}-\mathrm{W}-\mathrm{O}_{\text {wat }}$ \\
\hline \multirow[t]{4}{*}{ PESU 1:4 $\left(0.88 \mathrm{H}_{2} \mathrm{O} \mathrm{nm}^{-3}\right)$} & $n_{\text {pairs }}^{I J}$ & 21.7 & 20.9 & 4.7 & 6.4 & 2.7 & 1.0 \\
\hline & $n_{\text {intra pairs }}^{I J}$ & 5.2 & 2.1 & 0.4 & & & \\
\hline & $n_{\text {visited }}^{I J}$ & 7.5 & 2.6 & 0.3 & 10.5 & 2.7 & 2.7 \\
\hline & $n_{\text {formed }}^{I J}$ & 0.32 & 0.05 & 0.002 & 0.24 & 0.02 & 0.04 \\
\hline \multirow[t]{4}{*}{ PPSU 1:4 $\left(0.48 \mathrm{H}_{2} \mathrm{O} \mathrm{nm}^{-3}\right)$} & $n_{\text {pairs }}^{I J}$ & 6.9 & 12.0 & 5.7 & 2.3 & 1.6 & 0.6 \\
\hline & $n_{\text {intra pairs }}^{I J}$ & 2.2 & 0.8 & 0.4 & & & \\
\hline & $n_{\text {visited }}^{I J}$ & 2.4 & 1.4 & 0.3 & 3.9 & 1.8 & 1.5 \\
\hline & $n_{\text {formed }}^{I J}$ & 0.11 & 0.04 & 0.002 & 0.10 & 0.02 & 0.03 \\
\hline \multirow[t]{4}{*}{ PSU 1:4 $\left(0.41 \mathrm{H}_{2} \mathrm{O} \mathrm{nm}^{-3}\right)$} & $n_{\text {pairs }}^{I J}$ & 5.1 & 8.3 & 4.1 & 1.8 & 1.0 & 0.4 \\
\hline & $n_{\text {intra pairs }}^{I J}$ & 1.9 & 0.8 & 0.4 & & & \\
\hline & $n_{\text {visited }}^{I J}$ & 2.1 & 1.1 & 0.2 & 3.1 & 1.1 & 1.1 \\
\hline & $n_{\text {formed }}^{I J}$ & 0.10 & 0.03 & 0.002 & 0.07 & 0.01 & 0.01 \\
\hline
\end{tabular}

The numbers of pairs of hydrophilic sites $\left(n_{\text {pairs }}^{J J}\right)$ per $\mathrm{nm}^{3}$ potentially able to form a bridge, average numbers of bridges formed per configuration per $\mathrm{nm}^{3}\left(n_{\text {formed }}^{J J}\right)$, and the cumulative numbers of different bridges visited by $\mathrm{H}_{2} \mathrm{O}$ molecules in 4 ns of simulations per nm ${ }^{3}$ ( $\left.n_{\text {visited }}^{\prime J}\right)$ in the PESU $1: 4$, PPSU 1:4 and PSU 1:4 models. The intramolecular contribution $n_{\text {intrapairs }}^{I J}$ to $n_{\text {pairs }}^{I J}$ is also displayed.

the importance of this possibility. In any case, it is highly likely that the formation of a bridge involves some local rearrangement of the atoms in proximity.

Values of $n_{\text {pairs }}^{I J}$ are displayed in Table 7 for the PESU 1:4, PPSU 1:4 and PSU 1:4 models. The values for the other hydrated and dry systems are very similar with just a slight trend of decreasing numbers of potential bridges with increasing water content. This would be consistent with the observed volume swelling and thus does not show any evidence of water promoting the number of potential bridging sites. Also shown in Table 7 are the average number of bridges actually formed per configuration per $\mathrm{nm}^{3}$ in our simulations ( $n_{\text {formed }}^{I J}$ ) and the cumulative number of different bridges visited by $\mathrm{H}_{2} \mathrm{O}$ molecules in 4 ns of simulations per $\mathrm{nm}^{3}\left(n_{\text {visited }}^{I J}\right)$. It can be seen that the PESU model has more "potential bridges" ( $\left.n_{\text {pairs }}^{I J}\right)$ than PPSU which in turn has more "potential bridges" than PSU. This trend is in agreement with the concentration of the total number of polymer hydrophilic sites $\left(\mathrm{O}_{\text {sulf }}\right.$ plus $\left.\mathrm{O}_{\text {eth }}\right)$ of the different models: $\sim 10.7, \sim 7.8$, and $\sim 6.5$ polymer hydrophilic sites $/ \mathrm{nm}^{3}$ in the dry PESU, PPSU, and PSU, respectively. This trend is also consistent with that of the experimental equilibrium water uptakes at saturation of these polymers. If we consider just the sulfonic oxygens then their concentrations are: $\sim 7.2$, $\sim 3.9$, and $\sim 3.2$ per $\mathrm{nm}^{3}$, for the dry PESU, PPSU, and PSU, respectively.

As stated above, it is not certain that all these potential bridges are really accessible due to the neglect of steric hindrance in the calculation. However, the number of distinct bridges, i.e., between two specific acceptor atoms, actually visited increases inexorably during the simulation (curves not shown) suggesting that steric hindrance is not an insurmountable problem. It is, though, not possible to define an upper limit to the number of distinct accessible bridges without extending the length of the simulations considerably.
Concerning the equilibrium uptake of water at saturation, the PESU 1:4 and PPSU 1:4 models are those considered as the more representative of the experimental water saturation, whereas the PSU 1:4 model has more water than at saturation. In any case, the number of bridges actually formed at any one instant in our models is very much lower than the cumulative number of distinct bridges visited during the simulation, and we speculate from this that it is, thus, certainly lower than the number of accessible bridges. Previously we had shown that water uptake at saturation can not be explained simply by the number of accessible hydrophilic sites. Here we propose that it can not be explained either by the number of accessible bridging sites.

It can also be noted that the number of "potential intramolecular bridges" $n_{\text {intrapairs }}^{I J}$ is already higher than the number of bridges formed $n_{\text {formed }}^{\text {IJ }}$. It is also perhaps necessary to explain why the number of visited $\mathrm{W}-\mathrm{W}-\mathrm{W}$ and $\mathrm{P}-\mathrm{W}-\mathrm{W}$ bridges can be superior to the number of potential bridges. Here, we compare a dynamic analysis (cumulative number of distinct bridges visited) with a static one (potential bridges). As the water molecules are relatively mobile, many "new" potential bridges are formed as the water molecules diffuse with time and some will be visited. Ultimately this leads to the average (static) number of "potential bridges," $n_{\text {pairs }}^{I J}$ being inferior to the cumulative number of distinct ones visited, $n_{\text {visited }}^{I J}$.

\section{Water Clusters}

Experimentally, a common way to assess the degree of clustering of water molecules in polymer matrices is to plot curves of the volume fraction of water vs. water activity, as prescribed by the Zimm and Lundberg "cluster function" analysis. ${ }^{250}$ In this approach, the linearity in these sorption isotherms is interpreted as being due to the homogeneous dissolution of the water molecules in the polymer, whereas 
nonlinearity is thought to be related to the clustering of water molecules.

No consensus exists concerning the shapes of the sorption isotherms of the polysulfones in the literature. As far as PESU is concerned, sorption isotherms are found to be totally linear, ${ }^{64,108}$ whereas others propose a concavity at low activities ${ }^{199,200}$ and an upward curvature at high activities. $^{200}$ It is also reported that the low activity domain is not adequately resolved to talk about a concavity. ${ }^{203,249}$ For PSU, several authors find also linear curves, ${ }^{29,64,108,199,233}$ whereas other find a concavity at low activities with an upward curvature at high activities. ${ }^{16}$ To the best of our knowledge, PPSU sorption isotherms have only been published by Gaudichet et al. who find it to be linear, as in the case of PESU and PSU. ${ }^{64,108}$ A comparable discordance concerning the shapes of the sorption isotherms had previously been found for PMDA-ODA. ${ }^{156}$ In fact, in most of the cases, it appears that similar shapes of sorption isotherms can be interpreted differently depending on the author. Some remarks of authors put forward difficulties of interpretations. $^{203,233,249}$ Furthermore, we can not neglect the effect of the use of slightly different materials and equipment from one experiment to another.

Schult et al. have used the Zimm and Lundberg cluster function analysis on their PESU and PSU sorption isotherms. ${ }^{63}$ They interpret its variations by the presence of water clusters in the PSU for activities superior than 0.5. However, they interpret a similar plot of the cluster function in PESU in terms of plastification of the polymer instead of presence of water clusters. For them, the presence of water clusters should induce a decrease in the rate of water diffusion which is not observed in PESU. According to them, it means that no water clusters exist in this polymer. ${ }^{63}$ Yet, dielectric measurements on hydrated PESU, have been interpreted in terms of the presence of water clusters. ${ }^{251}$

Water clusters have been analyzed in the model hydrated polysulfone systems using the same method than previously described in the case of PMDA-ODA. ${ }^{156}$ We define water clusters through the aforementioned hydrogen bond criterion $\left(d_{\mathrm{H} \cdots \mathrm{O}} \leq 2.4 \AA\right)$. A water molecule is considered to belong to the same cluster if it is hydrogen bonded to any other member of the cluster. The cluster size is then obtained from a standard analysis of the interconnected water molecules. We emphasize that this does not necessarily mean that each water molecule in a cluster has an H-bond with all other members of the cluster. This definition also means that water molecules in the cluster can also be H-bonded to the polymer. Probability density distribution functions for cluster sizes have been obtained from the production simulations. These distribution functions are shown in a form where they have been weighted by the cluster size in Figure 15 so as to give the amount of water involved in clusters of different sizes. For comparison with the relaxed systems, we have also calculated average "as inserted" distributions by repeating the initial water introduction step five times, with five different water configurations, on each dry polysulfone starting configuration.

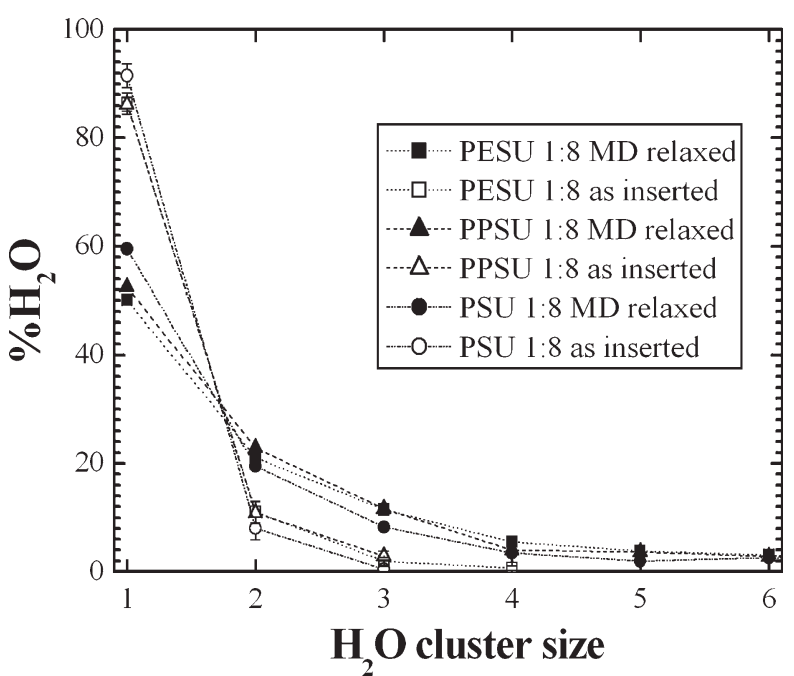

FIGURE 15 The average amount of water found in clusters of a given size in the PESU 1:8, the PPSU 1:8, and the PSU 1:8 systems at $373 \mathrm{~K}$. The averaged MD relaxed results are compared with those for the as inserted water molecules (see text for details).

First of all, we can see that, in the MD relaxed systems, there are few large water clusters at the relatively low water content, $n_{\mathrm{H}_{2} \mathrm{O}}: n_{\mathrm{SO}_{2}}=1: 8$, reported in Figure 15 and $50 \%-60 \%$ of all water is isolated having no $\mathrm{H}$-bonds with other water molecules. The amount of water involved in clusters of 7 or more molecules are negligible. This suggests that water clusters are much less favorably formed in polysulfones than in PMDA-ODA. ${ }^{156}$ However, as already found in MD simulations of hydrated polymers, clusters can be larger than two or three water molecules. ${ }^{115,117,124,130,132,136,137,140,145}$ If we compare the average distribution of the amount of water in clusters for the "MD relaxed" systems with the "as-inserted" distributions, we can see that about $90 \%$ of the "as inserted" waters molecules are isolated from all others with clusters of four or more molecules extremely rare. This is in complete contrast to our previous results for PMDA-ODA where less than $30 \%$ of the "as inserted" water was isolated and clusters of 10 were initially present. ${ }^{156}$ This confirms the results of the comparisons of the distributions of probe accessible volumes already shown in Figure 5 where the PMDA-ODA model displays a significantly larger quantity of PAV and a wider distribution of hole sizes than the polysulfone models.

The amount of water not involved in clusters, "isolated water," is given as a function of the water content in Table 8. There is a clear decrease in the proportion of isolated water with increasing water content, as might be expected. This is consistent with the results shown for the potential energies, or the specific interactions. It is also interesting to note that about $1 / 12$ of the $\mathrm{H}_{2} \mathrm{O}$ added to the PESU 1:4 are isolated, $\sim 1 / 6$ of the $\mathrm{H}_{2} \mathrm{O}$ added to the PPSU 1:4, and $\sim 1 / 5$ of the $\mathrm{H}_{2} \mathrm{O}$ added to the PSU sat. In other words, even for higher water contents than the experimental saturation, added $\mathrm{H}_{2} \mathrm{O}$ can be isolated. This means that, in the range of water 
TABLE 8 Percentage of "Isolated" Water Molecules, That is, Water Molecules Not Involved in Any Clusters, in the Hydrated Polysulfone Models as a Function of Their Water Contents

\begin{tabular}{llll}
\hline $\begin{array}{l}\text { Ratio } \\
n_{\mathrm{H}_{2} \mathrm{O}}: n_{\mathrm{SO}_{2}}\end{array}$ & $\begin{array}{l}\text { \% Isolated } \\
\text { Water in PESU }\end{array}$ & $\begin{array}{l}\text { \% Isolated } \\
\text { Water in PPSU }\end{array}$ & $\begin{array}{l}\text { \% Isolated } \\
\text { Water in PSU }\end{array}$ \\
$1: 8$ & 50.1 & 52.4 & 59.5 \\
$\sim 1: 6$ & & & 53.0 \\
$1: 4$ & 33.1 & 34.9 & 39.8 \\
$1: 2$ & 20.9 & 25.4 & 30.6
\end{tabular}

contents studied, the polysulfone models are unlikely to be "saturated" in isolated $\mathrm{H}_{2} \mathrm{O}$.

The comparison of the polysulfone models at the same $n_{\mathrm{H}_{2} \mathrm{O}}: n_{\mathrm{SO}_{2}}$ ratio (Table 8 ), gives the impression that more water molecules are involved in clusters in the order PESU $>$ PPSU > PSU. However, if we instead make the comparison at the same water concentrations this has the effect of collapsing the results for PPSU and PSU on to the same curve (not shown) whereas the PESU has now less water involved in clusters than PPSU and PSU at water concentrations which can be compared.

The average mean square radii of gyration of the water clusters $\left\langle S_{\text {clust }}^{2}\right\rangle$ are displayed as a function of cluster size in Figure 16 for polysulfones with $n_{\mathrm{H}_{2} \mathrm{O}}: n_{\mathrm{SO}_{2}}=1: 2$ and for PMDA-ODA. ${ }^{156}$ Results for $\left\langle S_{\text {clust }}^{2}>\right.$ are very similar at different water contents. Only the results for the higher water contents are thus shown in Figure 16. We can see that for a given cluster size, $\left\langle S_{\text {clust }}^{2}>\right.$ values are almost the same from one polymer to another. Discrepancies visible for large cluster sizes should mainly be related to the poor statistics available for these cluster sizes in polysulfones. It suggests that the shapes of water clusters should be similar in all these polymers. We had previously related the linear increase of $<S_{\text {clust }}^{2}>$ with the cluster size $N$ as being due to more open geometries rather than globular ones; the latter following the relationship:

$$
\left\langle S_{\text {clust }}^{2}\right\rangle \approx \frac{3}{5}\left(\frac{3 N m}{4 \pi \rho}\right)^{\frac{2}{3}}
$$

with $N$ the number of $\mathrm{H}_{2} \mathrm{O}$ molecules in the cluster and $\mathrm{m}$ the mass of a water molecule. Equation 17 is applicable in the limit that globular clusters have a uniform density given by that of bulk liquid water $\left(958.05 \mathrm{~kg} \mathrm{~m}^{-3}\right.$ at $373 \mathrm{~K}$ ). Figure 16 also displays $\left\langle S_{\text {clust }}^{2}\right\rangle$ calculated by this way ("Globular") and thus put forward the nonspherical geometries of the water clusters. This kind of geometry has already been observed in other simulation studies. ${ }^{98,115,136,137}$ Nevertheless, no simple or recurrent forms of clusters can be visually identified in the simulation movies. It appears that $\mathrm{H}_{2} \mathrm{O}$ molecules involved in a cluster can stay in their clusters, leave it and come back later, or leave it definitively under the timescale of the simulations. However, the water clusters persist during all the simulation, despite the changes in the constitutive members, without showing any evidence of displace- ment. This has also been observed in other simulation studies. ${ }^{140,141,150}$

\section{Short Time Water Mobility}

Our MD simulations being of relatively short duration, $\sim 5$ ns, with respect to real experiments, it is clear that only the very short time mobility of water molecules can be studied. All phenomena which occur on longer time scales are obviously beyond the range of this approach. With this in mind, the mean square displacements (MSD) for each type of atom in the dry and hydrated polysulfone systems have been calculated from the time-dependent positions, previously saved in coordinate trajectory files, in the following manner

$$
\operatorname{MSD}=\left\langle\left(\mathbf{r}(t)-\mathbf{r}\left(t_{0}\right)\right)^{2}\right\rangle
$$

where $\mathbf{r}$ is the position vector of an atom, and the average is performed over all possible time origins $t_{0}$. For the polymer atoms the MSDs are extremely small and in no case exceed 3 $\AA^{2}$ in 4000 ps. The curves obtained for water oxygens in the PESU 1:4, PPSU 1:2 and PSU 1:2 systems are shown on a log-log scale in Figure 17. For comparison the curve obtained for the PMDA-ODA system at $1.4 \mathrm{wt} \%$ water is also shown. All four of these systems are at similar water concentrations $\left(\sim 0.8 \mathrm{H}_{2} \mathrm{O} / \mathrm{nm}^{3}\right)$. The MSDs of the water oxygens over 4000 ps in the hydrated polysulfone systems show that during this time the average root mean square displacements of the $\mathrm{H}_{2} \mathrm{O}$ in the different models are comprised between $\sim 10$ and $\sim 14 \AA$ A A comparison with the dotted line of slope 1 shows clearly that this time scale is insufficient to reach the Einstein diffusive regime of water in these polymers at $373 \mathrm{~K}$; the slopes being more in the region of 0.6-0.7. Up to a time interval of $\sim 1000$ ps water mobilities can be ranked in the four systems in the ascending order: PESU $<$ PPSU $<$ PSU $<$ PMDA-ODA. At times beyond 1000 ps the curves for PESU

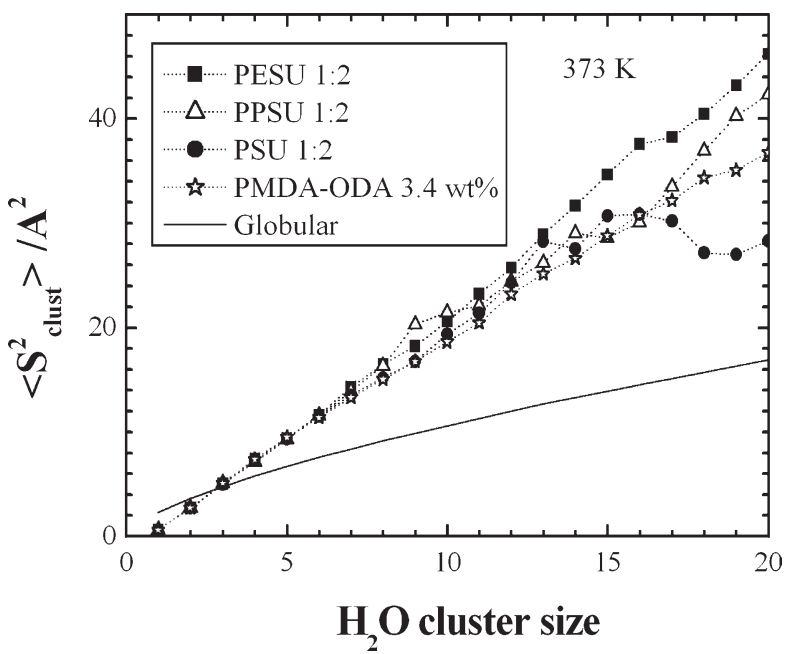

FIGURE 16 The mean square radii of gyration for the water clusters, $\left\langle S_{\text {clust }}^{2}\right\rangle$, as a function of cluster size. Results are displayed for the polysulfones systems with $n_{\mathrm{H}_{2} \mathrm{O}}: n_{\mathrm{SO}_{2}}=1: 2$, for a PMDA-ODA system, ${ }^{156}$ and for the theoretical values for globular clusters based on the expression given in eq 17. 


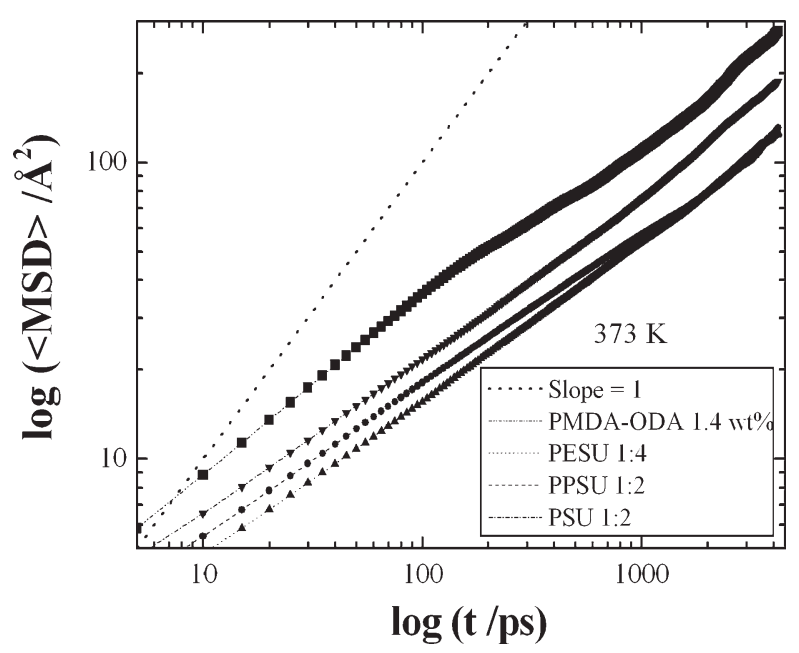

FIGURE 17 Mean square displacements (MSD) averaged over all time origins for water oxygens in the PESU 1:4, PPSU 1:2, and PSU 1:2 systems. For comparison, the curve obtained for the PMDA-ODA system at $1.4 \mathrm{wt} \%$ water is also shown. ${ }^{156}$ All four of these systems are at similar water concentrations.

and PPSU become intermingled so predictions of the order in the limiting diffusion coefficients from short time data are hazardous. The higher MSDs in the case of PMDA-ODA are again consistent with the higher PAV and cluster size distribution which confer, at least at short times, greater mobility.

To study in more detail the mechanisms by which the water molecules move, simulation movies, created with $\mathrm{VMD}^{252}$ from configurations stored at 5 ps intervals, were first studied. These showed that occasional jumps of $\mathrm{H}_{2} \mathrm{O}$ molecules occurred within the time of two consecutive frames. As the disparity of jump durations and lengths make it difficult to make a quantitative study, free of arbitrary parameters to define what a jump is, it was decided instead to extract the self part of the Van Hove correlation function, $G_{S}(r, t)$. This function gives the probability density that an atom moves a distance $r$ in a time interval $t$. The $G_{S}(r, t)$ functions of the sulfonic oxygens, the ether oxygens and the water oxygens in the PESU 1:2 system have been reported in Figure 18 for time intervals of 5 and 100 ps. As might be expected from the MSDs, the $\mathrm{O}_{\text {sulf }}$ and $\mathrm{O}_{\text {eth }}$ distributions just show a single peak at around $1 \AA$ which only slightly broadens and diminishes in height between 5 and 100 ps. The distribution for water oxygens shows a quite different behavior with a first peak centered at slightly more than $1 \AA$ and a substantial tail off towards higher $r$ values. It is also evident that a lower second peak is formed at a distance of $\sim 3 \AA$. This feature is evident also in the other systems and in the case of PMDA-ODA also. It persists in the case of polysulfones for at least 1000 ps. It is a clear signature of a hopping mechanism existing between neighboring binding sites which we presume to be on the polymer.

To characterize further these hops, the population of water molecules has been determined which move, in a time interval of 5 ps, a distance superior to a critical threshold, $r_{0}$, defined from the maximum distance that a hydrophilic site on the polymer can move in the same time. The reasoning being that a water molecule hydrogen bonded to a site on the polymer can not move a distance $r>r_{0}$ without there being a high probability of breaking the H-bond. From the $\mathrm{O}_{\text {sulf }}$ and $\mathrm{O}_{\text {eth }} G_{\mathrm{S}}(r, t)$ functions at $5 \mathrm{ps}$, we have chosen an upper limit distance of $r_{0}=2.5 \AA$. Percentages of $\mathrm{H}_{2} \mathrm{O}$ moving a distance superior to $r_{0}$ are thus calculated from $\int_{r=r_{0}}^{+\infty} G_{\mathrm{S}}(r, t) d r$ and are reported in Table 9. It appears that the percentages of water molecules moving a distance superior to $2.5 \AA$ in 5 ps is comprised between $\sim 13$ and $\sim 22 \%$ depending on the system considered. We have previously seen (see Fig. 17) that water molecules were more mobile in the order PSU > PPSU > PESU at shorter times, which is corroborated here by the higher percentages of $\mathrm{H}_{2} \mathrm{O}$ moving more than $2.5 \AA$ in 5 ps in the PSU models in comparison with the other polysulfone models. We have also seen from the number of $\mathrm{O}_{\text {sulf }}, \mathrm{O}_{\text {eth }}$, and $\mathrm{O}_{\text {wat }}$ sites visited by one $\mathrm{H}_{2} \mathrm{O}$ in a period of 4000 ps that, taking into account the higher concentration of hydrophilic sites, water moves less in PESU. Part of the explanation for this result could be that the $\mathrm{O}_{\text {sulf }}$ sites act as a trap for the water molecules; as the significantly longer $\mathrm{H}$-bond decorrelation times of the $\mathrm{O}_{\text {sulf }}$ atoms demonstrate. Then the higher concentration of $\mathrm{O}_{\text {sulf, }}$ particularly in PESU where more water is to be found in bridging sites, leads to a higher probability of encountering another $\mathrm{O}_{\text {sulf }}$ and, thus, shorter displacements when a jump does occur. Further detailed analyses would be required to confirm, or infirm, this hypothesis, but it is almost certain that the influence of the other water molecules cannot be neglected.

\section{CONCLUSIONS}

Atomistic simulations of three long-chain amorphous polysulfone models (PESU, PPSU, and PSU) have been carried out in dry and hydrated states with water contents lower and higher than their respective experimental saturations. These dense models, each one containing more than 48,000 atoms,

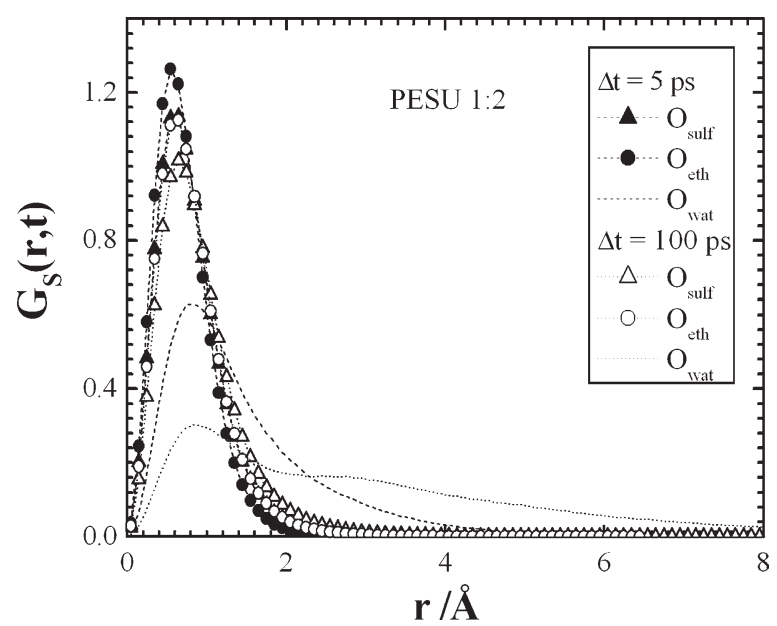

FIGURE 18 The self parts of the Van Hove functions, $G_{S}(r, t)$, evaluated at time intervals of 5 and 100 ps for sulfonic oxygens, $\mathrm{O}_{\text {sulf, }}$ ether oxygens, $\mathrm{O}_{\text {eth }}$, and water oxygens, $\mathrm{O}_{\text {wat, }}$ in the system PESU 1:2. 
TABLE 9 Probabilities That a Water Molecule Moves a Distance Superior to $2.5 \AA$ in 5 ps in the PESU, the PPSU, and the PSU Models at $373 \mathrm{~K}$

\begin{tabular}{llllll}
\hline System & Probability (\%) & System & Probability (\%) & System & Probability (\%) \\
PESU 1:8 & 14.9 & PPSU 1:8 & 19.5 & PSU 1:8 & PSU sat \\
& & & & PSU 1:4 & 21.8 \\
PESU 1:4 & 14.7 & PPSU 1:4 & 19.8 & PSU 1:2 & 21.5 \\
PESU 1:2 & 13.2 & PPSU 1:2 & 17.5 & 20.8
\end{tabular}

with chain lengths similar than those experimentally used, have been generated by the hybrid pivot Monte Carlo-Molecular Dynamics technique, which has been validated for $n_{\text {bonds }}$ $=4$. The dry bulk models prepared in this way relax, without any persuasion, to densities reasonably close to experimental values; at $300 \mathrm{~K}$, the relative differences between the experimental densities and the model densities are $\sim 1.6 \%$ for the PESU, $\sim 1.7 \%$ for the PPSU, and $0.7 \%$ for the PSU.

Hydrated systems have been simulated for $5 \mathrm{~ns}$ at $373 \mathrm{~K}$ to obtain sufficient displacements of water molecules $(\sim 10-14$ $\AA$ in $4 \mathrm{~ns}$ ) for a reasonably representative sampling of different environments. All three model polysulfone systems swell to a very similar degree with the addition of water. The swelling is essentially linear above $\sim 0.3$ wt $\%$ water with a slope consistent with that from experimental studies. This is a quite different behavior to that found in PMDA-ODA where swelling only occurred above $\sim 3$ wt $\%$ water. This result correlates with the findings for the probe accessible volume which is significantly higher in PMDA-ODA thus leading to an initial hole-filling mechanism that is practically absent in the polysulfones. Further analysis of the probe accessible volume shows that water increases the size of the holes and creates some others in the polysulfone matrices without creating any cavitation. Water is also found to occupy these holes.

The swelling also leads to a decrease (in absolute values) of the intermolecular polymer-polymer energies. The polymerwater and water-water interactions are preponderant in giving negative values of the mixing enthalpies in the different systems. Although the sum of the water-polymer and waterwater energies is proportional to water content the individual contributions are not. There is a general tendency for the water-polymer contribution to diminish in importance whilst a compensatory increase occurs in the water-water term. This results from a gradual change in the $\mathrm{P}-\mathrm{W}-\mathrm{P}$ and $\mathrm{P}-\mathrm{W}-$ $\mathrm{W}$ bridging patterns with water concentration.

A study of the preferential sites of interactions indicates that the water molecules form hydrogen bonds with oxygens of the sulfonic groups $\left(\mathrm{O}_{\text {sulf }}\right)$, ether oxygens $\left(\mathrm{O}_{\text {eth }}\right)$, and also with other water molecules $\left(\mathrm{O}_{\text {wat }}\right)$. H-bonds with $\mathrm{O}_{\text {sulf }}$ are stronger and persist longer. About $70 \%$ of the $\mathrm{H}_{2} \mathrm{O}$ in the PESU, and $55 \%$ in the PPSU and PSU are hydrogen bonded to two hydrophilic sites at the same time, and so form bridges between these sites. These bridges are mainly formed between two polymer sites (P-W-P) and between one polymer site and one other $\mathrm{H}_{2} \mathrm{O}(\mathrm{P}-\mathrm{W}-\mathrm{W})$. A detailed analysis of these bridges showed that the minimum and maximum distances which can separate two hydrophilic sites spanned by a water bridge are
2.4 and $6 \AA$, respectively. With these limits we have been able to determine, from the corresponding radial distribution functions, the average numbers of pairs of hydrophilic sites which could potentially form bridging sites. These numbers are considerably higher than the actual number of bridges formed in each configuration of our simulations. Although the calculation does not take into account bridges that are unlikely to form due to steric hindrance, the cumulative number of distinct different bridges actually formed during the course of the simulations is considerably in excess of the instantaneous number of bridges formed, even at water contents close to experimental saturation. It thus seems unlikely that the equilibrium water uptake at saturation can be explained in a simple way by the number of accessible bridging sites.

Water clusters of a fairly limited size $\left(<7 \mathrm{H}_{2} \mathrm{O}\right)$ have been found in the different hydrated polysulfone systems. This is in stark contrast to the PMDA-ODA hydrated models previously simulated which displayed a larger range of cluster sizes. This result again correlates with the findings for the probe accessible volumes. At comparable water concentrations, the tendency to form clusters is less marked in PESU whereas PPSU and PSU behave similarly. The clusters have a similar morphology in each polysulfone and their structure is more open than that of a dense droplet.

The $\mathrm{H}_{2} \mathrm{O}$ molecules diffuse in part by a hopping mechanism in the polymer matrix. The populations of water oxygens which move more than $2.5 \AA$ in 5 ps, i.e., hop, is higher in the order PSU $>$ PPSU $>$ PESU. This is also coherent with the mean square displacements of the $\mathrm{H}_{2} \mathrm{O}$ molecules in the three polymer matrices at times less than 1000 ps. The $4 \mathrm{~ns}$ time scale of the simulations is too short to obtain the limiting Einstein regime diffusion coefficients.

We express gratitude to Solvay Advanced Polymers for providing samples of PESU, PPSU, and PSU. We also acknowledge the University of Savoie and EDF for the provision of computer time on their MUST cluster and Rendvous machines, respectively. This work was funded by the joint "COPOLA" (Composite and Polymer Ageing) research program involving EDF, NEXANS France, LABORELEC, the ANDRA, the CEA, the INRA, and the CNRS.

\section{REFERENCES AND NOTES}

1 Jabarin, S. A.; Lofgren, E. A. Polymer Engineering and Science $1986,26,620-625$.

2 Langevin, D.; Grenet, J.; Saiter, J. M. Eur Polym J 1994, 30, 339-345. 
3 Bastioli, C.; Guanella, I.; Romano, G. Polym Compos 1990, 11, 1-9.

4 Toda, T.; Yoshida, H.; Fukunishi, K. Polymer 1995, 36, 699-706.

5 Hodge, R. M.; Edward, G. H.; Simon, G. P. Polymer 1996, 37, 1371-1376.

6 Laporta, M.; Pegoraro, M.; Zanderighi, L. Phys Chem Chem Phys 1999, 1, 4619-4628.

7 Forsyth, M.; Sun, J.; Macfarlane, D. R.; Hill, A. J. J Polym Sci Part B: Polym Phys 2000, 38, 341-350.

8 Hodge, R. M.; Bastow, T. J.; Edward, G. H.; Simon, G. P.; Hill, A. J. Macromolecules 1996, 29, 8137-8143.

9 Robertson, J. E.; Ward, T. C.; Hill, A. J. Polymer 2000, 41, $6251-6262$

10 Dlubek, G.; Redmann, F.; Krause-Rehberg, R. J Appl Polym Sci 2002, 84, 244-255.

$11 \mathrm{Hu}$, Y. S.; Mehta, S.; Schiraldi, D. A.; Hiltner, A.; Baer, E. J Polym Sci Part B: Polym Phys 2005, 43, 1365-1381.

12 Kim, Y. S.; Dong, L.; Hickner, M. A.; Glass, T. E.; Webb, V.; McGrath, J. E. Macromolecules 2003, 36, 6281-6285.

13 Sun, N.; Yang, J.; Shen, D. Polymer 1999, 40, 6619-6622.

14 Park, J.-S.; Park, J.-W.; Ruckenstein, E. J Appl Polym Sci 2001, 82, 1816-1823.

15 Karimi, M.; Heuchel, M.; Albrecht, W.; Hofmann, D. J Membr Sci 2007, 292, 80-91.

16 Schult, K. A.; Paul, D. R. J Polym Sci Part B: Polym Phys 1997, 35, 655-674.

17 Han, S. O.; Drzal, L. T. Eur Polym J 2003, 39, 1791-1799.

18 Verdu, J. In Sciences et Techniques de L'ingénieur; WEKA: Paris, France, 2000; pp 1-8.

19 Barthélémy, E.; Munier, C.; Verdu, J. J Mater Sci Lett 2001, 20, 1143-1145.

20 Akele, N.; Thominette, F.; Paris, D.; Pays, M. F.; Verdu, J. J Mater Sci Lett 1996, 15, 1001-1002.

21 Verdu, J. In Sciences et Techniques de L'ingénieur; WEKA: Paris, France, 1990; pp 1-17.

22 Stamm, A. J.; Seborg, R. M. J Phys Chem 1935, 39, 133-142.

23 Benczedi, D.; Tomka, I.; Escher, F. Macromolecules 1998, 31, 3055-3061.

24 Lim, B. S.; Nowick, A. S.; Lee, K.; Viehbeck, A. J Polym Sci Part B: Polym Phys 1993, 31, 545-555.

25 Miyagi, Z.; Tanaka, K. Polymer 1975, 16, 441-444.

26 Stober, E. J.; Seferis, J. C.; Keenan, J. D. Polymer 1984, 25, 1845-1852.

27 Launay, A.; Thominette, F.; Verdu, J. J Appl Polym Sci 1999, 73, 1131-1137.

28 Buchhold, R.; Nakladal, A.; Gerlach, G.; Sahre, K.; Müller, M.; Eichhorn, K.-J.; Herold, M.; Gauglitz, G. J Electrochem Soc 1998, 145, 4012-4018.

29 Rowe, B. W.; Freeman, B. D.; Paul, D. R. Macromolecules 2007, 40, 2806-2813.
30 Sahre, K.; Eichhorn, K.-J.; Günther, M.; Suchaneck, G.; Gerlach, G. Anal Bioanal Chem 2004, 378, 396-401.

31 Jou, J.-H.; Huang, R.; Huang, P.-T.; Shen, W.-P. J Appl Polym Sci 1991, 43, 857-875.

32 Martin, J. R.; Gardner, R. J. Polym Eng Sci 1981, 21, 557-565.

33 Adamson, M. J. J Mater Sci 1980, 15, 1736-1745.

34 Blumentritt, B. F. Polym Eng Sci 1978, 18, 1216-1219.

35 McKague, E. L., Jr.; Reynolds, J. D.; Halkias, J. E. J Appl Polym Sci 1978, 22, 1643-1654.

36 Starkweather, H. W. J Appl Polym Sci 1959, 2, 129-133.

37 White, H. J. J.; Eyring, H. Text Res J 1947, 17, 523-553.

38 Robeson, L. M.; Farnham, A. G.; McGrath, J. E. In Molecular Basis of Transitions and Relaxations; Boyer, R. F.; Meier, D. J., Eds.; Gordon \& Breach: London, 1978; pp 405-425.

39 Dhakal, H. N.; Zhang, Z. Y.; Richardson, M. O. W. Compos Sci Technol 2007, 67, 1674-1683.

40 Kim, H. J.; Seo, D. W. Int J Fatigue 2006, 28, 1307-1314.

41 Merdas, I.; Thominette, F.; Verdu, J. J Appl Polym Sci 2000, 77, 1445-1451.

42 Baschek, G.; Hartwig, G.; Zahradnik, F. Polymer 1999, 40, 3433-3441.

43 De Nève, B.; Shanahan, M. E. R. Polymer 1993, 34, 5099-5105.

44 Ogura, K.; Fujii, A.; Shiigi, H.; Nakayama, M.; Tonosaki, T. J Electrochem Soc 2000, 147, 1105-1109.

45 Ducéré, V.; Bernès, A.; Lacabanne, C. Sens Actuators B 2005, 106, 331-334.

46 Bellucci, F.; Khamis, I.; Senturia, S. D.; Latanision, R. M. J Electrochem Soc 1990, 137, 1778-1784.

47 Deligoz, H.; Yalcinyuva, T.; Ozgumus, S.; Yildirm, S. J Appl Polym Sci 2006, 100, 810-818.

48 Jacobson, P. A.; Rosa, L. G.; Kraemer, K.; Ducharme, S.; Dowben, P. A. Mater Lett 2007, 61, 1137-1141.

49 Tcharkhtchi, A.; Bronnec, P. Y.; Verdu, J. Polymer 2000, 41, 5777-5785.

50 Yang, D. K.; Koros, W. J.; Hopfenberg, H. B.; Stannett, V. T. J Appl Polym Sci 1986, 31, 1619-1629.

51 Thominette, F.; Merdas, I.; Verdu, J. In Polyimides and Other High Temperature Polymers; Mittal, K. L., Ed.; VSP: Utrecht, The Netherlands, 2003; pp 255-266.

52 Ghorbel, I.; Thominette, F.; Spiteri, P.; Verdu, J. J Appl Polym Sci 1995, 55, 163-171.

53 Ghorbel, I.; Akele, N.; Thominette, F.; Spiteri, P.; Verdu, J. J Appl Polym Sci 1995, 55, 173-179.

54 Jacques, B.; Werth, M.; Merdas, I.; Thominette, F.; Verdu, J. Polymer 2002, 43, 6439-6447.

55 Launay, A.; Thominette, F.; Verdu, J. Polym Degrad Stab 1994, 46, 319-324.

56 Launay, A.; Thominette, F.; Verdu, J. Polym Degrad Stab $1999,63,385-389$. 
57 Merdas, I.; Thominette, F.; Verdu, J. Polym Degrad Stab 2003, 79, 419-425.

58 Salmon, L.; Thominette, F.; Pays, M. F.; Verdu, J. Compos Sci Technol 1997, 57, 1119-1127.

59 Salmon, L.; Thominette, F.; Pays, M. F.; Verdu, J. Polym Compos 1999, 20, 715-724.

60 Shanahan, M. E. R.; Auriac, Y. Polymer 1998, 39, 1155-1164.

61 Xiao, G. Z.; Shanahan, M. E. R. J Polym Sci Part B: Polym Phys 1997, 35, 2659-2670.

62 Puffr, R.; Sabenda, J. J Polym Sci Part C: Polym Symp 1967, $16,79-93$.

63 Schult, K. A.; Paul, D. R. J Polym Sci Part B: Polym Phys 1996, 34, 2805-2817.

64 Gaudichet-Maurin, E. Caractérisation et Vieillissement D'une Membrane D'ultrafiltration D'eau, Ph.D. Thesis, Ecole Nationale Supérieure d'arts et métiers, Paris, France, 2005.

65 Starkweather, H. W. J Polym Sci Part B: Polym Lett 1963, 1, 133-138.

66 Starkweather, H. W. Macromolecules 1975, 8, 476-479.

67 Starkweather, H. W. ACS Symp Ser 1980, 127, 433-440.

68 Yang, D. K.; Koros, W. J.; Hopfenberg, H. B.; Stannett, V. T. J Appl Polym Sci 1985, 30, 1035-1047.

69 Barrie, J. A.; Sagoo, P. S.; Johncock, P. J Appl Polym Sci 1987, 33, 2253-2258.

70 Okamoto, K.-I.; Tanihara, N.; Watanabe, H.; Tanaka, K.; Kita, H.; Nakamura, A.; Kusuki, Y.; Nakagawa, K. J Polym Sci Part B Polym Phys 1992, 30, 1223-1231.

71 Larobina, D.; Lavorgna, M.; Mensitieri, G.; Musto, P.; Vautrin, A. Macromol Symp 2007, 247, 11-20.

72 Ree, M.; Han, H.; Gryte, C. C. High Perform Polym 1994, 6, 321-333.

73 Sacher, E.; Susko, J. R. J Appl Polym Sci 1979, 23, 2355-2364.

74 Pranjoto, H.; Denton, D. D. J Appl Polym Sci 1991, 42, 75-83.

75 Hubbell, J. W. H.; Brandt, H.; Munir, Z. A. J Polym Sci Polym Phys Ed 1975, 13, 493-507.

76 Musto, P.; Mascia, L.; Mensitieri, G.; Ragosta, G. Polymer 2005, 46, 4492-4503.

77 Merdas, I.; Thominette, F.; Verdu, J. J Appl Polym Sci 2000, 77, 1439-1444.

78 Quinn, F. X.; Kampff, E.; Smyth, G.; McBrierty, V. J. Macromolecules 1988, 21, 3191-3198.

79 Smyth, G.; Quinn, F. X.; McBrierty, V. J. Macromolecules 1988, 21, 3198-3204.

80 Karlsson, L. E.; Jannasch, P. J Membr Sci 2004, 230, 61-70.

81 Ping, Z. H.; Nguyen, Q. T.; Chen, S. M.; Zhou, J. Q.; Ding, Y. D. Polymer 2001, 42, 8461-8467.

82 Murphy, D.; De Pinho, M. N. J Membr Sci 1995, 106, 245-257.

83 Cotugno, S.; Mensitieri, G.; Musto, P.; Sanguigno, L. Macromolecules 2005, 38, 801-811.
84 Mensitieri, G.; Lavorgna, M.; Larobina, D.; Scherillo, G.; Ragosta, G.; Musto, P. Macromolecules 2008, 41, 4850-4855.

85 Mensitieri, G.; Lavorgna, M.; Musto, P.; Ragosta, G. Polymer 2006, 47, 8326-8336.

86 Musto, P.; Ragosta, G.; Mensitieri, G.; Lavorgna, M. Macromolecules 2007, 40, 9614-9627.

87 Wan, L. S.; Huang, X. J.; Xu, Z. K. J Phys Chem B 2007, 111, 922-928.

88 Cotugno, S.; Larobina, D.; Mensitieri, G.; Musto, P.; Ragosta, G. Polymer 2001, 42, 6431-6438.

89 Ichikawa, K.; Mori, T.; Kitano, H.; Fukuda, M.; Mochizuki, A.; Tanaka, M. J Polym Sci Part B: Polym Phys 2001, 39, 2175-2182.

90 Pereira, M. R.; Yarwood, J. J Chem Soc Faraday Trans 1996, 92, 2731-2735.

91 Pereira, M. R.; Yarwood, J. J Chem Soc Faraday Trans 1996, 92, 2737-2743.

92 Mura, C.; Yarwood, J.; Swart, R.; Hodge, D. Polymer 2001, $42,4141-4152$.

93 Servaty, R.; Schiller, J.; Binder, H.; Arnold, K. Int J Biol Macromol 2001, 28, 121-127.

94 Maréchal, Y.; Milas, M.; Rinaudo, M. Biopolymers 2003, 72, 162-173.

95 Ngono, Y.; Maréchal, Y. J Polym Sci Part B: Polym Phys 2000, 38, 329-340.

96 Ngono, Y.; Maréchal, Y. J Polym Sci Part B: Polym Phys 2001, 39, 1129-1136.

97 Ngono, Y.; Marechal, Y.; Mermilliod, N. J Phys Chem B 1999, 103, 4979-4985.

98 Mijovic, J.; Zhang, H. Macromolecules 2003, 36, 1279-1288.

99 Musto, P.; Ragosta, G.; Scarinzi, G.; Mascia, L. J Polym Sci Part B: Polym Phys 2002, 40, 922-938.

100 Van Alsten, J. G.; Coburn, J. C. Macromolecules 1994, 27, 3746-3752.

101 Fontanella, J. J.; Bendler, J. T.; Schuele, D. E.; Edmondson, C. A.; Lomax, J. F. J Non-Cryst Solids 2007, 353, 4528-4532.

102 Xu, G.; Gryte, C. C.; Norwick, A. S.; Li, S. Z.; Pak, Y. S.; Greenbaum, S. G. J Appl Phys 1989, 66, 5290-5296.

103 Ghi, P. Y.; Hill, D. J. T.; Whittaker, A. K. Biomacromolecules 2002, 3, 991-997.

104 Li, S. Z.; Chen, R. S.; Greenbaum, S. G. J Polym Sci Part B: Polym Phys 1995, 33, 403-409.

105 Li, S. Z.; Pak, Y. S.; Adamic, K.; Greenbaum, S. G.; Lim, B. S.; Xu, G.; Nowick, A. S. J Electrochem Soc 1992, 139, 662-667.

106 Waters, J. F.; Likavec, W. R.; Ritchey, W. M. J Appl Polym Sci 1994, 53, 59-70.

107 Enns, J. B.; Gillham, J. K. J Appl Polym Sci 1983, 28, 2831-2846.

108 Gaudichet-Maurin, E.; Thominette, F.; Verdu, J. J Appl Polym Sci 2008, 109, 3279-3285.

109 Merdas, I.; Tcharkhtchi, A.; Thominette, F.; Verdu, J.; Dean, K.; Cook, W. Polymer 2002, 43, 4619-4625. 
110 Merdas, I.; Thominette, F.; Tcharkhtchi, A.; Verdu, J. Compos Sci Technol 2002, 62, 487-492.

111 Van Krevelen, D. W. Properties of Polymers. Their Correlation with Chemical Structure. Their Numerical Estimation and Prediction from Additive Group Contribution; Elsevier: Amsterdam, 1990.

112 Barton, A. F. M. Handbook of Solubility and Other Cohesion Parameters; CRC Press, Boca Raton, FL, 1983.

113 Ahn, W.-Y.; Kalinichev, A. G.; Clark, M. M. J Membr Sci 2008, 309, 128-140.

114 Knopp, B.; Suter, U. W. Macromolecules 1997, 30, 6114-6119.

115 Goudeau, S.; Charlot, M.; Vergelati, C.; Müller-Plathe, F. Macromolecules 2004, 37, 8072-8081.

116 Goudeau, S.; Charlot, M.; Müller-Plathe, F. J Phys Chem B 2004, 108, 18779-18788.

117 Netz, P. A.; Dorfmüller, T. J Phys Chem B 1998, 102, 4875-4886.

118 Kotelyanskii, M. J.; Wagner, N. J.; Paulaitis, M. E. J Membr Sci 1998, 139, 1-16.

119 Kotelyanskii, M. J.; Wagner, N. J.; Paulaitis, M. E. Comput Theor Polym Sci 1999, 9, 301-306.

120 Tönsing, T.; Oldiges, C. Phys Chem Chem Phys 2001, 3, $5542-5549$

121 Bharadwaj, R. K. Macromolecules 2002, 35, 5334-5336.

122 Nick, B.; Suter, U. W. Comput Theor Polym Sci 2001, 11, 49-55.

123 Madkour, T. M. Chem Phys 2001, 274, 187-198.

124 Tamai, Y.; Tanaka, H.; Nakanishi, K. Macromolecules 1996, $29,6750-6760$.

125 Tamai, Y.; Tanaka, H.; Nakanishi, K. Macromolecules 1996, 29, 6761-6769.

126 Tamai, Y.; Tanaka, H. Phys Rev E Stat Phys Plasmas, Fluids Relat Interdiscip Topics 1999, 59, 5647-5654.

127 Müller-Plathe, F.; Van Gunsteren, W. F. Polymer 1997, 38, 2259-2268

128 Müller-Plathe, F. Macromolecules 1998, 31, 6721-6723.

129 Müller-Plathe, F. J Membr Sci 1998, 141, 147-154.

130 Müller-Plathe, F. J Chem Phys 1998, 108, 8252-8263.

131 Karlsson, G. E.; Johansson, T. S.; Gedde, U. W.; Hedenqvist, M. S. J Macromol Sci Phys 2002, 41, 185-206.

132 Kucukpinar, E.; Doruker, P. Polymer 2004, 45, 3555-3564.

133 Borodin, O.; Bedrov, D.; Smith, G. D. J Phys Chem B 2002, $106,5194-5199$

134 Ennari, J.; Neelov, I.; Sunholm, F. Polymer 2004, 45, 4171-4179.

135 Ennari, J.; Elomaa, M.; Sundholm, F. Polymer 1999, 40, 5035-5041.

136 Elliott, J. A.; Hanna, S.; Elliott, A. M. S.; Cooley, G. E. Phys Chem Chem Phys 1999, 1, 4855-4863.

137 Elliott, J. A.; Paddison, S. J Phys Chem Chem Phys 2007, 9, 2602-2618.
138 Pozuelo, J.; Riande, E.; Saiz, E.; Compan, V. Macromolecules 2006, 39, 8862-8866.

$139 \mathrm{Hu}, \mathrm{N} . ;$ Chen, R.; Hsu, A. Polym Int 2006, 55, 872-882.

140 Fukuda, M. J Chem Phys 1998, 109, 6476-6485.

141 Tamai, Y.; Tanaka, H.; Nakanishi, K. Macromolecules 1994, 27, 4498-4508.

142 Tamai, Y.; Tanaka, H.; Nakanishi, K. Macromolecules 1995, $28,2544-2554$.

143 Fritz, L.; Hofmann, D. Polymer 1997, 38, 1035-1045.

144 Tamai, Y.; Tanaka, H.; Nakanishi, K. Fluid Phase Equilib 1995, 104, 363-374.

145 Fukuda, M.; Kuwajima, S. J Chem Phys 1998, 108, 3001-3009.

146 Dömötör, G.; Hentschke, R. Macromol Theor Simul 2004, 13, 506-511.

147 Mijovic, J.; Zhang, H. J Phys Chem B 2004, 108, 2557-2563.

$148 \mathrm{Wu}, \mathrm{C} . ;$ Xu, W. Polymer 2007, 48, 5440-5448.

149 Kucukpinar, E.; Doruker, P. Polymer 2003, 44, 3607-3620.

150 Kucukpinar, E.; Doruker, P. Polymer 2006, 47, 7835-7845.

151 Chen, Z.; Gu, Q.; Zou, H.; Zhao, T.; Wang, H. J Polym Sci Part B: Polym Phys 2007, 45, 884-891.

152 Entrialgo-Castaño, M.; Lendlein, A.; Hofmann, D. Adv Eng Mater 2006, 8, 434-439.

153 Pal, S.; Maiti, P. K.; Bagchi, B.; Lindenberg, K.; Oshanin, G.; Tachiya, M. J Phys: Condens Matter 2005, 17, S4317-S4331.

154 Mazur, A. K. J Am Chem Soc 2002, 124, 14707-14715.

155 Cheng, Y. K.; Rossky, P. J. Nature 1998, 392, 696-699.

156 Marque, G.; Neyertz, S.; Verdu, J.; Prunier, V.; Brown, D. Macromolecules 2008, 41, 3349-3362.

157 Fan, C. F.; Hsu, S. L. Macromolecules 1991, 24, 6244-6249.

158 Fan, C. F.; Hsu, S. L. Macromolecules 1992, 25, 266-270.

159 Hamerton, I.; Heald, C. R.; Howlin, B. J. Model Simul Mater Sci Eng 1996, 4, 151-159.

160 Niemela, S.; Leppanen, J.; Sundholm, F. Polymer 1996, 37, 4155-4165.

161 Wang, X. Y.; in 't Veld, P. J.; Lu, Y.; Freeman, B. D.; Sanchez, I. C. Polymer 2005, 46, 9155-9161.

162 Heuchel, M.; Böhning, M.; Hölck, O.; Siegert, M. R.; Hofmann, D. J Polym Sci Part B: Polym Phys 2006, 44, 1874-1897.

163 Hölck, O.; Heuchel, M.; Böhning, M.; Hofmann, D. J Polym Sci Part B: Polym Phys 2008, 46, 59-71.

164 Hölck, O.; Siegert, M. R.; Heuchel, M.; Bohning, M. Macromolecules 2006, 39, 9590-9604.

165 Shi, T.; Jiang, W.; An, L.; Li, B. Macromol Theory Simul 2001, 10, 232-236.

166 McKechnie, J. I.; Brown, D.; Clarke, J. H. R. Macromolecules 1992, 25, 1562-1567.

167 Neyertz, S. Soft Mater 2007, 4, 15-83.

168 Brown, D.; Clarke, J. H. R.; Okuda, M.; Yamazaki, T. J Chem Phys 1994, 100, 1684-1692. 
169 Brown, D.; Clarke, J. H. R.; Okuda, M.; Yamazaki, T. J Chem Phys 1994, 100, 6011-6018.

170 Brown, D.; Clarke, J. H. R.; Okuda, M.; Yamazaki, T. J Chem Phys 1996, 104, 2078-2082.

171 Pinel, E.; Brown, D.; Bas, C.; Mercier, R.; Albérola, N. D.; Neyertz, S. Macromolecules 2002, 35, 10198-10209.

172 Neyertz, S. Macromol Theory Simul 2007, 16, 513-524.

173 Neyertz, S.; Brown, D. J Chem Phys 1995, 102, 9725-9735.

174 Neyertz, S.; Brown, D. J Chem Phys 1996, 104, 10063.

175 Neyertz, S.; Brown, D. J Chem Phys 2001, 115, 708-717.

176 Neyertz, S.; Brown, D. Macromolecules 2004, 37, 10109-10122.

177 Neyertz, S.; Brown, D.; Clarke, J. H. R. J Chem Phys 1996, 105, 2076-2088.

178 Neyertz, S.; Douanne, A.; Brown, D. Macromolecules 2005, 38, 10286-10298.

179 Neyertz, S.; Douanne, A.; Brown, D. J Membr Sci 2006, $280,517-529$.

180 Neyertz, S.; Brown, D.; Douanne, A.; Bas, C.; Alberola, N. D. J Phys Chem B 2002, 106, 4617-4631.

181 Hammonds, K. D.; Ryckaert, J.-P. Comput Phys Commun 1991, 62, 336-351.

182 Ewald, P. P. Ann Phys 1921, 64, 253-287.

183 Smith, W. Comput Phys Commun 1992, 67, 392-406.

184 Clark, M.; Cramer, R. D., III; Van Opdenbosch, N. J Comput Chem 1989, 10, 982-1012.

185 Allinger, N. L.; Fan, Y. J Comput Chem 1993, 14, 655-666.

186 Frisch, M. J.; Trucks, G. W.; Schlegel, H. B.; Scuseria, G. E.; Robb, M. A.; Cheeseman, J. R.; Montgomery, J. A., Jr.; Vreven, T.; Kudin, K. N.; Burant, J. C.; Millam, J. M.; Iyengar, S. S.; Tomasi, J.; Barone, V.; Mennucci, B.; Cossi, M.; Scalmani, G.; Rega, N.; Petersson, G. A.; Nakatsuji, H.; Hada, M.; Ehara, M.; Toyota, K.; Fukuda, R.; Hasegawa, J.; Ishida, M.; Nakajima, T.; Honda, Y.; Kitao, O.; Nakai, H.; Klene, M.; Li, X.; Knox, J. E.; Hratchian, H. P.; Cross, J. B.; Bakken, V.; Adamo, C.; Jaramillo, J.; Gomperts, R.; Stratmann, R. E.; Yazyev, O.; Austin, A. J.; Cammi, R.; Pomelli, C.; Ochterski, J. W.; Ayala, P. Y.; Morokuma, K.; Voth, G. A.; Salvador, P.; Dannenberg, J. J.; Zakrzewski, V. G.; Dapprich, S.; Daniels, A. D.; Strain, M. C.; Farkas, O.; Malick, D. K.; Rabuck, A. D.; Raghavachari, K.; Foresman, J. B.; Ortiz, J. V.; Cui, Q.; Baboul, A. G.; Clifford, S.; Cioslowski, J.; Stefanov, B. B.; Liu, G.; Liashenko, A.; Piskorz, P.; Komaromi, I.; Martin, R. L.; Fox, D. J.; Keith, T.; Al-Laham, M. A.; Peng, C. Y.; Nanayakkara, A.; Challacombe, M.; Gill, P. M. W.; Johnson, B.; Chen, W.; Wong, M. W.; Gonzalez, C.; Pople, J. A. Gaussian 03, Revision D.02; Gaussian Inc., Pittsburgh, USA, 2004.

187 Marque, G., Absorption D'eau par les Polymères, Ph.D. Thesis, Université de Savoie: Chambéry, France, 2009.

188 Berendsen, H. J. C.; Grigera, J. R.; Straatsma, T. P. J Phys Chem 1987, 91, 6269-6271.

189 Allen, M. P.; Tildesley, D. J. Computer Simulation of Liquids; Clarendon Press, Oxford, England, 1987.

190 Brown, D. The gmq User Manual Version 4, Chambéry, France, 2008. Available at: http://www.Imops.univ-savoie.fr/ brown/gmq.html. Accessed on 11th August, 2010.
191 Lal, M. Mol Phys 1969, 17, 57-64.

192 Flory, P. J. The Statistical Mechanics of Chain Molecules; Hanser Publishers: New York, 1988.

193 Brown, D.; Clarke, J. H. R. Comput Phys Commun 1991, 62, 360-369.

194 Berendsen, H. J. C.; Postma, J. P. M.; Van Gunsteren, W. F.; DiNola, A.; Haak, J. R. J Chem Phys 1984, 81, 3684-3690.

195 Brown, D.; Neyertz, S. Mol Phys 1995, 84, 577-595.

196 Fincham, D. Mol Simul 1994, 13, 1-9.

197 Barth, C.; Wolf, B. A. Macromol Chem Phys 2000, 201, 365-374.

198 Johnson, R. N.; Farnham, A. G.; Clendinning, R. A.; Hale, W. F.; Merriam, C. N. J Polym Sci Part A-1: Polym Chem 1967, 5, 2375-2398.

199 Swinyard, B. T.; Sagoo, P. S.; Barrie, J. A.; Ash, R. J Appl Polym Sci 1990, 41, 2479-2485.

200 Schult, K. A.; Paul, D. R. J Polym Sci Part B: Polym Phys 1997, 35, 993-1007.

201 Aitken, C. L.; McHattie, J. S.; Paul, D. R. Macromolecules 1992, 25, 2910-2922.

202 Clark, J. H.; Denness, J. E. Polymer 1994, 35, 2432-2437.

203 Singh, V. B.; Walsh, D. J. J Macromol Sci Part B: Phys 1986, 25, 65-87.

204 El-Hibri, J.; Weinberg, S. A. In Encyclopedia of Polymer Science and Technology; Mark, H. F., Ed.; Wiley-Interscience: Hoboken, NJ, 2004; pp 1-25.

205 Yamamoto, T.; Furukawa, H. J Appl Polym Sci 2001, 80, 1609-1618.

206 Ghosal, K.; Chern, R. T.; Freeman, B. D. J Polym Sci Part B: Polym Phys 1993, 31, 891-893.

207 Callaghan, T. A.; Paul, D. R. J Polym Sci Part B: Polym Phys 1994, 32, 1847-1880.

208 Linares, A.; Acosta, J. L.; Rodrıguez, S. J Appl Polym Sci 2006, 100, 3474-3482.

209 Aitken, C. L.; Koros, W. J.; Paul, D. R. Macromolecules 1992, 25, 3651-3658.

210 Ghosal, K.; Chern, R. T.; Freeman, B. D.; Daly, W. H.; Negulescu, I. I. Macromolecules 1996, 29, 4360-4369.

211 Aguilar-Vega, M.; Paul, D. R. J Polym Sci Part B: Polym Phys 1993, 31, 1599-1610.

212 McHattie, J. S.; Koros, W. J.; Paul, D. R. Polymer 1991, 32, 840-850.

213 Robeson, L. M. Polym Eng Sci 1969, 9, 277-281.

214 Maeda, Y.; Paul, D. R. J Polym Sci Part B: Polym Phys $1987,25,957-980$.

215 Lagunas-Fuentes, C.; Ruiz-Trevino, F. A. J Polym Sci Part B: Polym Phys 2004, 42, 226-231.

216 Hofmann, D.; Heuchel, M.; Yampolskii, Y.; Khotimskii, V.; Shantarovich, V. Macromolecules 2002, 35, 2129-2140.

217 Merdas, I., Vieillissement Humide du Polyetherimide, Ph.D. Thesis, Ecole Nationale Supérieure d'arts et métiers, Paris, France, 2000. 
218 Pospiech, D.; Gottwald, A.; Jehnichen, D.; Friedel, P.; John, A.; Harnisch, C.; Voigt, D.; Khimich, G.; Bilibin, A. Colloid Polym Sci 2002, 280, 1027-1037.

219 Bas, C.; Mercier, R.; Sanchez-Marcano, J.; Neyertz, S.; Alberola, N. D.; Pinel, E. J Polym Sci Part B: Polym Phys 2005, 43, 2413-2426.

220 Matsuura, T.; Blais, P.; Sourirajan, S. J Appl Polym Sci $1976,20,1515-1531$.

221 Bondi, A. Physical Properties of Molecular Crystals, Liquids and Gases; John Wiley \& Sons: New York, 1968.

222 Aitken, C. L.; Koros, W. J.; Paul, D. R. Macromolecules 1992, 25, 3424-3434.

223 Chung, C. I.; Sauer, J. A. J Polym Sci Part A-2: Polym Phys 1971, 9, 1097-1115.

224 Khayet, M.; Garcia-Payo, M. C. Desalination 2009, 245, 494-500.

225 Neder, R. B.; Proffen, T. Diffuse Scattering and Defect Structure Simulations: A Cook Book Using the Program DISCUS; Oxford University Press: Oxford, 2009.

226 Lufrano, F.; Squadrito, G.; Patti, A.; Passalacqua, E. J Appl Polym Sci 2000, 77, 1250-1256.

227 Kim, I.-W.; Lee, J.; Jho, J. Y.; Park, H. C.; Won, J.; Yong, S. K.; Guiver, M. D.; Robertson, G. P.; Dai, Y. Macromolecules 2001, 34, 2908-2913.

228 Boyd, R. H.; Pant, P. V. K. Macromolecules 1991, 24, 4078-4083.

229 Lee, S.; Mattice, W. L. Comput Theor Polym Sci 1999, 9, 57-61.

230 Nagel, C.; Schmidtke, E.; Günther-Schade, K.; Hofmann, D.; Fritsch, D. Macromolecules 2000, 33, 2242-2248.

231 Pant, P. V. K.; Boyd, R. H. Macromolecules 1993, 26, 679-686.

232 Malhotra, B. D.; Pethrick, R. A. Eur Polym J 1983, 19, 457-459.

233 Karimi, M.; Albrecht, W.; Heuchel, M.; Kish, M. H.; Frahn, J.; Weigel, T.; Hofmann, D.; Modarress, H.; Lendlein, A. J Membr Sci 2005, 265, 1-12.
234 Handbook of Chemistry and Physics; Lide, D. R., Ed.; CRC Press/Taylor \& Francis: Boca Raton, FL, 2009.

235 Greenspan, L. J Res Natl Bur Stand Sect A 1977, 81A, 89-96.

236 Tang, A.-M.; Cui, Y.-J. Can Geotech J 2005, 42, 287-296.

237 Giacomelli Penon, M.; Picken, S. J.; Wubbenhorst, M.; de Vos, G.; Van Turnhout, J. Rev Sci Instrum 2006, 77, 115107-1-115107-6.

238 Speakman, J. C. The Hydrogen Bond and Other Intermolecular Forces; Chemical Society: London, 1975.

239 Pimentel, G. C.; McClellan, A. L. The Hydrogen Bond; W. H. Freeman: San Francisco, 1960.

240 Rapaport, D. C. Mol Phys 1983, 50, 1151-1162.

241 Stillinger, F. H. Adv Chem Phys 1975, 31, 1-101.

242 Lanczos, C. J Soc Indus Appl Math Ser B: Numer Anal 1964, 1, 86-96.

243 Bellucci, F.; Nicodemo, L. Corrosion 1993, 49, 235-247.

244 Han, H.; Chung, H.; Gryte, C. C.; Shin, T. J.; Ree, M. Polymer 1999, 40, 2681-2685.

245 Han, H.; Gryte, C. C.; Ree, M. Polymer 1995, 36, 1663-1672.

246 Han, H.; Seo, J.; Ree, M.; Pyo, S. M.; Gryte, C. C. Polymer 1998, 39, 2963-2972.

247 Moylan, C. R.; Best, M. E.; Ree, M. J Polym Sci Part B: Polym Phys 1991, 29, 87-92.

248 Okamoto, K. In Polyimides: Fundamentals and Applications; Gosh, M. K.; Mittal, K. L., Eds.; Marcel Dekker: New York, USA, 1996; pp 265-278.

249 Singh, V. B.; Barrie, J. A.; Walsh, D. J. J Appl Polym Sci 1986, 31, 295-299.

250 Zimm, B.; Lundberg, J. L. J Phys Chem 1956, 60, 425-428.

251 Allen, G.; McAinsh, J.; Jeffs, G. M. Polymer 1971, 12, 85-100.

252 Humphrey, W.; Dalke, A.; Schulten, K. J. Mol Graphics 1996, 14, 33-38. 